\title{
AVALIAÇÃO DA QUALIDADE EM SERVIÇOS: UMA ANÁLISE COM RELAÇÃO À PERCEPÇÃO DOS DISCENTES DE UMA INSTITUIÇÃO DE ENSINO SUPERIOR
}

\section{SERVICE QUALITY EVALUATION: AN ANALYSIS OF THE STUDENTS PERCEPTION OF A HIGHER EDUCATION INSTITUTION}

\author{
Sthéfany Marilac Silva* E-mail: sthefanymarilac@gmail.com \\ Sandra Miranda Neves* E-mail: sandraneves@unifei.edu.br \\ Henrique Duarte Carvalho* E-mail: henrique.carvalho@unifei.edu.br \\ Carlos Henrique de Oliveira* carlos.henrique@unifei.edu.br \\ *Universidade Federal de Itajubá (Unifei), Itabira, MG
}

\begin{abstract}
Resumo: No Brasil, os anos 2000 foram marcados pela reestruturação do ensino superior, o que resultou em um crescimento considerável de instituições de ensino tanto no setor público, quanto no privado. Nesse contexto, surgiu como um desafio avaliar e acompanhar o desempenho dessas instituições. Assim, este estudo teve como objetivo identificar as lacunas existentes entre as expectativas e percepções dos discentes de uma Instituição Pública de Ensino Superior com relação à qualidade dos serviços prestados. Para atender a esse objetivo, o método de pesquisa adotado foi o levantamento de dados tipo Survey. Como ferramenta de análise, foi utilizado um questionário baseado na escala ServQual, que permite inferir sobre cinco aspectos relacionados aos serviços (tangibilidade, responsividade, confiabilidade, garantia e empatia). A análise considerou a prestação de serviços pelos setores de Ensino, Pesquisa, Extensão e Serviços Administrativos da instituição. Como resultados principais, observou-se que a dimensão Tangibilidade obteve a melhor avaliação em todos os setores e a dimensão Confiabilidade é aquela que apresenta o maior Gap negativo. Esses resultados permitiram identificar oportunidades de melhoria para cada um dos setores analisados.
\end{abstract}

Palavras-chave: Qualidade em serviços. Instituição de ensino. ServQual

Abstract: In Brazil, the 2000's were marked by the reconstruction of higher education, which resulted in a considerable growth of educational institutions in both the public and private sectors. In this context, a challenge was emerged to evaluate and monitor the performance of these institutions. Thus, this study aims to identify the gaps between the expectations and perceptions of the students in a Public Institution of Higher Education in relation to the quality of services provided. In order to meet this objective, the research method adopted was that of a data collection survey. As a tool for analysis, a questionnaire based on the ServQual scale was used, which allowed to infer five aspects related to the services (tangibility, responsiveness, reliability, assurance and empathy). The analysis was carried out in the Research, Extension, Administrative and Teaching Departments of the institution. As for the main results, it was observed that the Tangibility aspect obtained the best evaluation in all sectors while the Reliability aspect was the one that presented the highest negative Gap. The results permitted the identification of opportunities of betterment for each of the sectors analyzed.

Keywords: Service quality. Education institution. ServQual.

\section{INTRODUÇÃO}

Nos anos 2000, as Instituições de Ensino Superior (IES) passaram por um pro- 
cesso de reestruturação em resposta à necessidade de descentralizar e expandir o número de vagas disponíveis no ensino superior brasileiro (PIZZIO, 2015). Políticas públicas como o Programa Universidade para Todos (ProUni), criado em 2005 com o objetivo de conceder bolsas integrais e parciais em Instituições Privadas de Educação Superior para alunos provenientes da rede pública em troca de incentivos fiscais (BRASIL, 2005), e o Programa de Apoio a Planos de Reestruturação e Expansão das Universidades Federais (Reuni), lançado em 2007 com o objetivo principal de ampliar a permanência e o acesso à educação superior (BRASIL, 2007), transformaram a realidade da educação superior no país. Com isso, houve um crescimento no interesse da comunidade acadêmica em acompanhar o desempenho dessas instituições, a fim de participar e influenciar nas decisões de alocação dos recursos disponíveis (SARAIVA, 2004 apud CID et al., 2010). Entretanto, em 2016 o Ministério da Educação teve um corte de $\mathrm{R} \$ 4,277$ bilhões no seu orçamento (BRASIL, 2016). Torna-se, assim, um desafio, avaliar o desempenho dessas instituições, estabelecer indicadores de qualidade e mensurá-los a partir da percepção dos seus principais interessados (ou stakeholders).

Um dos principais stakeholders de uma instituição de ensino superior são os discentes. Entender os benefícios esperados por essa parte interessada na qualidade do ensino superior pode ajudar a encontrar novas soluções para o uso eficiente de recursos (DEGTJARJOVA; LAPINA; FREIDENFELDS, 2018). Assim, diante do cenário apresentado, o objetivo deste trabalho é identificar as lacunas existentes entre as expectativas e percepções dos discentes de uma Instituição Pública de Ensino Superior com relação à qualidade dos serviços prestados. Para atender ao objetivo geral estabelecido pretende-se: identificar a percepção dos discentes quanto à qualidade relacionada aos setores de Ensino, Pesquisa, atividades de Extensão e Serviços Administrativos da instituição; identificar os pontos fortes e os pontos fracos da IES em questão e identificar oportunidades de melhoria.

A pesquisa foi conduzida por meio de um levantamento tipo Survey realizado a partir da aplicação de um questionário baseado na escala ServQual. A Sevqual é uma ferramenta que permite avaliar o desempenho de acordo com as lacunas existentes entre o serviço esperado e o percebido pelo cliente, tendo como base cinco dimensões: Tangibilidade, confiabilidade, responsividade, garantia e empatia. 
Após uma análise de trabalhos semelhantes na literatura, foi possível levantar duas hipóteses $(H)$, a serem confirmadas ou refutadas ao final da pesquisa:

$\mathbf{H}_{1}$ : A dimensão Responsividade, dimensão que avalia a disponibilidade de uma empresa em ajudar o cliente e providenciar um pronto atendimento, apresentará o maior Gap entre a qualidade percebida e a expectativa dos discentes da Instituição de Ensino Superior.

$\mathbf{H}_{2}$ : Os discentes que participam de alguma entidade estudantil, tais como centros acadêmicos e equipes de competição tecnológica, possuem uma visão diferente com relação à qualidade dos serviços prestados pela instituição em comparação com os demais alunos.

Ressalta-se, que o objetivo do trabalho não é avaliar a qualidade da instituição de ensino como um todo, e sim avaliar a qualidade dos serviços prestados por alguns órgãos dentro da instituição de ensino, propondo melhorias pontuais. Para avaliar a instituição de ensino existem avaliações específicas que devem ser consideradas em seus processos de melhoria. As principais são as conduzidas pelo Ministério da Educação por meio do Sistema Nacional de Avaliação da Educação Superior (Sinaes) e coordenadas e supervisionadas pela Comissão Nacional de Avaliação da Educação Superior (Conaes). Essas avaliações consideram três eixos principais, as instituições, os cursos e o desempenho dos estudantes, em relação ao ensino, a pesquisa, a extensão, a responsabilidade social, o desempenho dos alunos, a gestão da instituição, o corpo docente e as instalações.

\section{EVOLUÇÃO DO NÚMERO DE INSTITUIÇÕES DE ENSINO SUPERIOR}

O Gráfico 1, elaborado a partir de dados extraídos dos Censos da Educação disponibilizados pelo Instituto Nacional de Estudos e Pesquisas Educacionais (Inep), apresenta a evolução do número de IES no Brasil no período de 1997 a 2014. 
Gráfico 1 - Crescimento do número de IES no período de 1997 a 2014

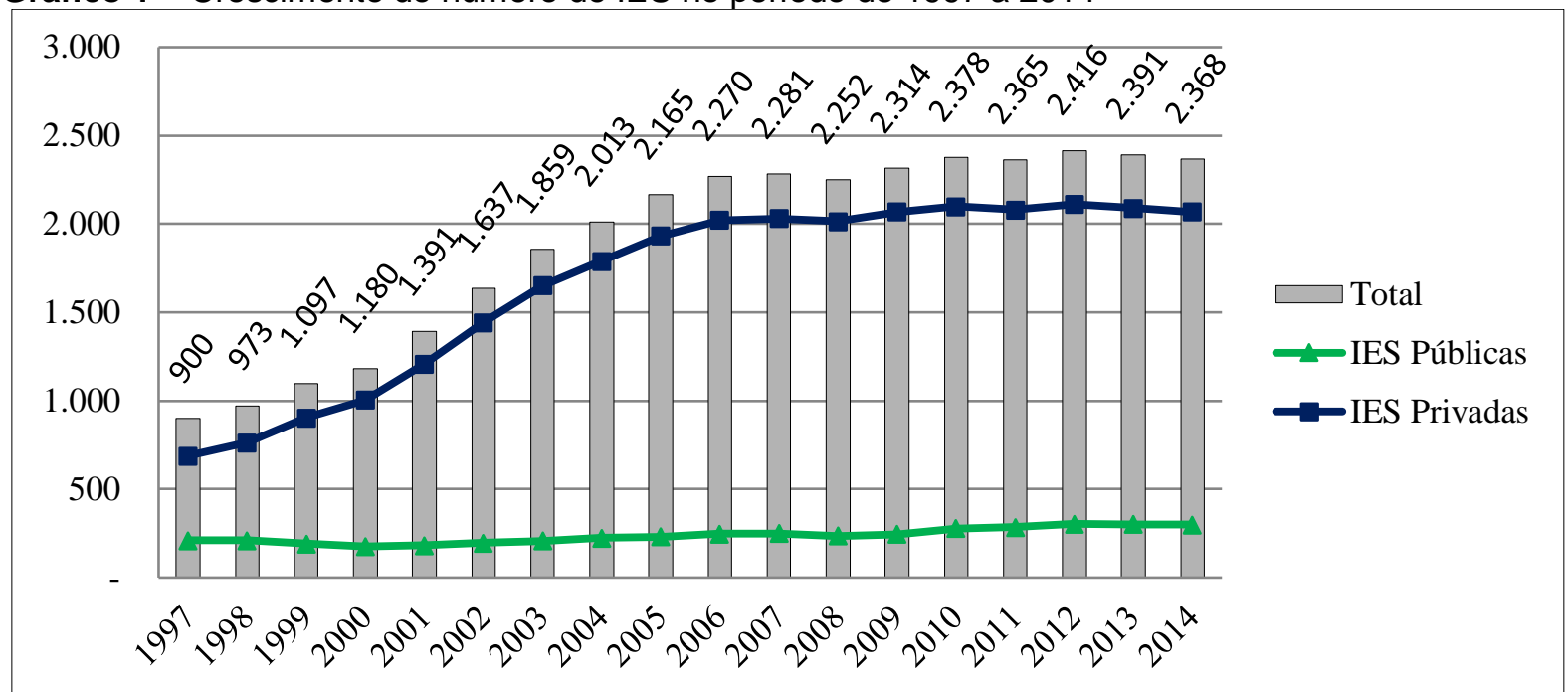

Fonte: Censo da Educação Superior, Inep (1997-2014)

A partir dos anos 2000 percebe-se um crescimento considerável no número de IES tanto no setor público quanto no privado. Esse crescimento foi resultado de um processo de criação de novas instituições e da expansão de universidades que já existiam a partir da construção de novos campi, cujo objetivo principal, segundo De Carvalho (2014), era reduzir as desigualdades regionais na educação superior no Brasil.

O aumento do número de IES veio acompanhado do crescimento das vagas disponíveis para ingresso de novos estudantes, o que exigia, sobretudo no setor público, um planejamento estratégico concreto para cada uma dessas novas instituições, além de infraestrutura física, qualificação docente e financiamentos, que não foram previstos a longo prazo (SOBRINHO, 2010). Ou seja, o aumento quantitativo de instituições, docentes, discentes e cursos de graduação no país levou a uma necessidade de se avaliar a qualidade dos serviços prestados pelas instituições públicas de ensino superior (RODRIGUES; DE LOURDES MACHADO; DE ARAÚJO, 2011). Quando o desempenho de uma instituição é mensurado, torna-se possível identificar pontos fortes e fracos, estabelecer metas e traçar planos de ação baseados nas suas prioridades, a fim de melhorar os seus resultados. Esses indicadores também podem ser utilizados para avaliar o desenvolvimento socioeconômico de um país (STABBACK, 2016). Algumas pesquisas nessa área indicam a importância da SevQual para avaliar a qualidade em instituições de ensino (LUPO, 2013; YOUSAPRONPAIBOON, 2014; GALEEVA, 2016; SILVA et al., 2016). 


\subsection{A escala ServQual}

A escala ServQual foi criada por Zeithaml, Parasuraman e Berry em 1988 como uma ferramenta para avaliar a qualidade percebida e utiliza como princípio as lacunas (ou gaps) existentes entre as percepções do desempenho de um serviço e as expectativas geradas pelos clientes. Essas lacunas são apresentadas na Figura 1.

Figura 1 - Gaps existentes na avaliação da qualidade em serviços

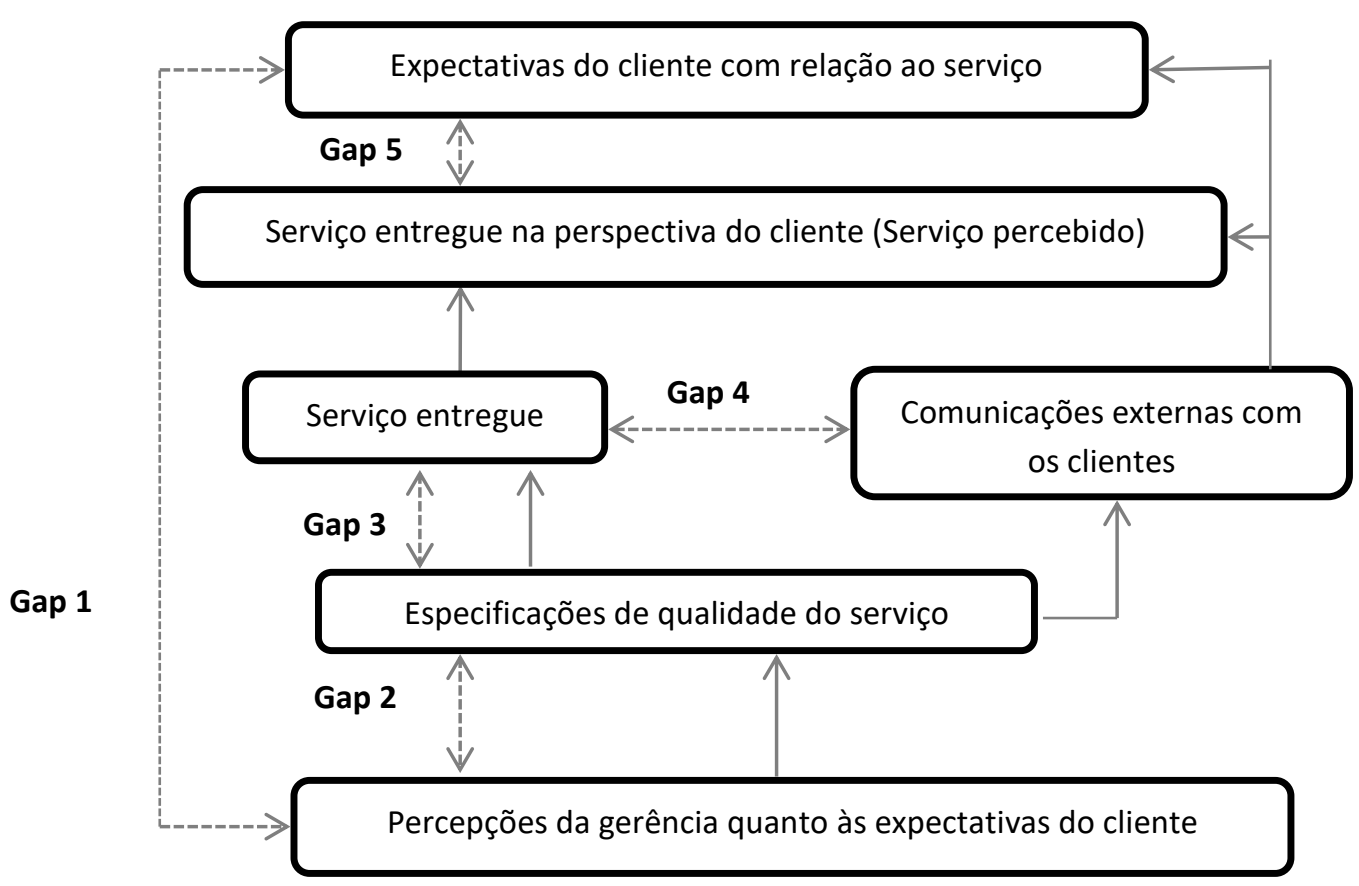

Fonte: Adaptado de Zeithaml, Parasuraman e Berry (1990).

Zeithaml, Parasuraman e Berry (1988) definiram cinco dimensões da qualidade, subdivididas em 22 afirmações no questionário ServQual, para avaliar a qualidade do serviço e ponderar as diferenças existentes entre as percepções e expectativas dos clientes (Quadro 1). 
Quadro 1 - As dimensões da qualidade em serviços

\begin{tabular}{|c|c|c|}
\hline Dimensões & Definições & Afirmações \\
Tangibilidade & $\begin{array}{c}\text { Aparência das instalações físicas, equipamentos, pessoal e } \\
\text { materiais de comunicação }\end{array}$ & $1,2,3$, e 4 \\
\hline Confiabilidade & $\begin{array}{c}\text { Habilidade em executar o serviço prometido com confiança e } \\
\text { precisão }\end{array}$ & $5,6,7,8$ e 9 \\
\hline Responsividade & $\begin{array}{c}\text { Disponibilidade para ajudar ao cliente e providenciar um } \\
\text { pronto atendimento }\end{array}$ & $10,11,12$ e 13 \\
\hline Garantia & $\begin{array}{c}\text { Conhecimento e cortesia dos colaboradores e a sua } \\
\text { habilidade em transmitir confiança e segurança }\end{array}$ & $14,15,16$, e 17 \\
\hline Empatia & $\begin{array}{c}\text { Capacidade da empresa em oferecer atenção individualizada } \\
\text { e serviço personalizado aos clientes }\end{array}$ & $18,19,20,21$ e 22 \\
\hline
\end{tabular}

Fonte: Adaptado de Zeithaml, Parasuraman e Berry (1990)

O questionário ServQual, então, relaciona essas cinco dimensões às expectativas dos clientes, ou seja, antes da realização de um serviço, e às percepções dos clientes após a prestação desse serviço. O que torna possível mensurar o Gap 5, apresentado na Figura 1, que é a base do desenvolvimento do questionário. O Gap 5 avalia a lacuna existente entre as expectativas de um cliente com relação a um serviço e a percepção do mesmo, conforme a Equação 1.

Gap = Percepção - Expectativa

Dessa forma, ao analisar as cinco dimensões da ServQual, é possível verificar que a percepção de um serviço irá superar as expectativas do cliente quando o Gap apresentar um valor positivo e, caso contrário, o mesmo apresentará um valor negativo.

\section{MATERIAIS E MÉTODOS}

O objeto de estudo desta pesquisa é uma Instituição Pública de Ensino Superior localizada no estado de Minas Gerais. A instituição é composta atualmente por 136 docentes, 77 técnicos administrativos, 80 anistiados e 1.787 discentes, distribuídos entre 9 cursos de graduação em engenharia. Segundo a Constituição Federal 
(BRASIL, 1988), as universidades devem obedecer ao princípio de indissociabilidade entre o ensino, a pesquisa e a extensão. Por essa razão, optou-se por avaliar esses pilares e, ainda, os serviços administrativos da instituição em questão.

Com relação aos procedimentos técnicos, esta pesquisa é classificada como Survey. O desenvolvimento do Survey foi baseado na metodologia proposta por Bryman e Bell (2011), trata-se, portanto, de uma abordagem quantitativa (SAMPIERI; COLLADO; LUCIO, 2012). Quanto aos objetivos pode ser classificada como uma pesquisa exploratória e quanto à natureza como uma pesquisa aplicada. Esse tipo de pesquisa geralmente visa gerar um modelo que possa ser utilizado em uma aplicação prática, voltado para a solução de problemas pontuais (GANGA, 2012).

Para a obtenção dos dados utilizou-se o questionário proposto por Zeithaml, Parasuraman e Berry (1988), denominado de ServQual. Esse questionário foi elaborado como uma ferramenta para avaliar a qualidade percebida e utiliza como princípio as lacunas (ou Gaps) existentes entre as percepções do desempenho de um serviço e as expectativas geradas pelos clientes. Na ocasião, para validar e verificar a confiabilidade da escala, os autores realizaram testes em quatro grupos com 190 consumidores cada.

Ao questionário foram acrescentadas algumas informações para identificar o perfil dos respondentes (como gênero, faixa etária, tipo de instituição em que fez a maior parte da formação e a qual curso de graduação o aluno está vinculado). Visando relacionar os Gaps identificados com as características da instituição avaliada, foram adicionadas, também, três questões abertas relacionadas a: Pontos fortes do serviço avaliado; Pontos fracos do serviço avaliado e se o aluno identificou alguma oportunidade/sugestão de melhoria para o serviço. Como não eram obrigatórias as respostas a essas questões, nem todos os respondentes optaram por completá-la. Sendo assim, as respostas obtidas foram agrupadas por similaridade e a frequência de citações das melhorias foi calculada de acordo com o número total de respostas obtidas para a pergunta em questão dentro do grupo avaliado.

O questionário teve como base a escala de 5 pontos (Likert, 1932), sendo: (1) discordo totalmente, (2) discordo parcialmente, (3) indiferente, (4) concordo parcialmente e (5) concordo totalmente. Como forma de validação, foi aplicado previamente a grupos de alunos que representavam cada setor definido (Quadro 2). Considerando o parecer desse grupo de alunos algumas afirmações foram ajustadas 
para melhor entendimento. Esses ajustes consistiram basicamente em constar alguns exemplos nas afirmações de forma a não gerar dúvidas durante o preenchimento. Como forma de selecionar os nomes dos alunos para os quais o questionário final seria enviado, utilizou-se da ferramenta de amostragem do software Excel (Microsoft). Essa ferramenta permite gerar uma lista de números aleatórios a partir da população especificada. Assim, cada número gerado poderia ser associado a um nome da lista de alunos em cada setor. A amostra necessária foi calculada considerando-se um nível de confiança de $95 \%$ e admitindo-se uma margem de erro máximo de 5\% (Quadro 2).

Quadro 2 - Número de indivíduos e amostras de cada grupo de trabalho

\begin{tabular}{|c|c|c|c|c|}
\hline Setor & População & Amostra & $\begin{array}{c}\text { Taxa mínima } \\
\text { de retorno }\end{array}$ & \multicolumn{1}{c|}{ Grupo de análise } \\
\hline Ensino & 1787 & 224 & 64 & $\begin{array}{l}\text { (1) Alunos matriculados na } \\
\text { Instituição. }\end{array}$ \\
\hline Pesquisa & 224 & 142 & 30 & $\begin{array}{l}\text { (2) Alunos vinculados a } \\
\text { projetos de Iniciação } \\
\text { Científica. }\end{array}$ \\
\hline Extensão & 249 & 152 & 30 & $\begin{array}{l}\text { (3) Alunos vinculados a } \\
\text { projetos de Extensão. }\end{array}$ \\
\hline $\begin{array}{c}\text { Serviços } \\
\text { Administrativos }\end{array}$ & 77 & 65 & 30 & $\begin{array}{l}\text { (4) Alunos envolvidos em } \\
\text { entidades de representação } \\
\text { estudantil. }\end{array}$ \\
\hline
\end{tabular}

Os grupos de análise foram segmentados para a avaliação de cada um dos pilares, considerando os seguintes aspectos:

(1) Todos os alunos matriculados na instituição devem cumprir uma carga horária obrigatória de disciplinas práticas e teóricas durante o curso de graduação. Dessa forma, todos os alunos estão aptos a avaliar o pilar referente ao ensino.

(2) O desenvolvimento de projetos de Iniciação Científica caracteriza-se pela realização de trabalhos científicos/tecnológicos junto a um professorpesquisador, possibilitando que esses alunos avaliassem o pilar referente à pesquisa.

(3) Os projetos de extensão caracterizam-se por envolver a comunidade acadêmica e a sociedade. Os alunos envolvidos nesses projetos foram convidados a avaliar o pilar referente à Extensão.

(4) Em um levantamento realizado junto à unidade de Representação Estudantil (RE) da instituição, pode-se constatar que, além do grupo que compõe o RE, existem ainda 9 Centros Acadêmicos compostos por alunos. Esses alunos estão 
constantemente em contato com coordenadores, professores e servidores técnicos/administrativos da instituição e, por essa razão, foram indicados para realizar a avaliação dos Serviços Administrativos da instituição.

A taxa mínima de respondentes necessárias para validar o levantamento tipo Survey foi calculada seguindo a Equação 2, proposta por Malhotra (2012), e corresponde ao percentual de respostas apuradas do total de questionários enviados.

Taxa de resposta $=\frac{\text { Número de entrevistas completadas }}{\text { Número de entrevistas elegíveis na amostra }}$

Fowler Junior (2011) afirma que levantamentos realizados por meio do correio ou internet apresentam, normalmente, taxas de respondentes entre $5 \%$ e $20 \%$ da amostra selecionada. Dessa forma, para a validação da pesquisa, faz-se necessário atingir uma taxa de resposta superior a $20 \%$. Além disso, Montgomery e Runger (2014) afirmam que o teorema do limite central geralmente admite $n \geq 30$ para considerar um resultado confiável.

O projeto e, portanto, o questionário a ser aplicado aos alunos, foi submetido a um Comitê de Ética em Pesquisa (CEP). Após as adequações solicitadas pelo comitê, a pesquisa foi aprovada para desenvolvimento. Os questionários foram, então, enviados por meio de formulário eletrônico para a lista de alunos definida. O software utilizado para a tabulação dos dados foi o Question Pro. As análises estatísticas foram realizadas a partir dos dados coletados entre os meses de outubro e de novembro de 2016.

\section{RESULTADOS E DISCUSSÕES}

\subsection{Análise Preliminar}

Considerando um total de 219 entrevistas completadas, a Tabela 1 apresenta o número de respondentes por setor. É importante destacar que em todos os grupos o número mínimo de respondentes necessários para validar estatisticamente este estudo foi alcançado, conforme definição apresentada na Seção 3. 
Tabela 1 - Número de respondentes para cada grupo de trabalho

\begin{tabular}{ccc}
\hline Setor & $\begin{array}{c}\text { Taxa mínima } \\
\text { de retorno }\end{array}$ & $\begin{array}{c}\text { Número de entrevistas } \\
\text { completadas }\end{array}$ \\
\hline Ensino & 64 & 88 \\
Pesquisa & 30 & 47 \\
Extensão & 30 & 52 \\
$\begin{array}{c}\text { Serviços } \\
\text { Administrativos }\end{array}$ & 30 & 32 \\
TOTAL & $\mathbf{1 5 4}$ & $\mathbf{2 1 9}$ \\
\hline
\end{tabular}

O Gráfico 2 apresenta o curso de graduação dos respondentes. Pode-se observar que houve a participação dos discentes de todos os 9 cursos da instituição avaliada, com destaque para os cursos de Engenharia de Produção (17\%), Engenharia Ambiental (13\%), Engenharia Elétrica e Engenharia de Materiais (12\%).

Gráfico 2 - Curso de graduação dos respondentes

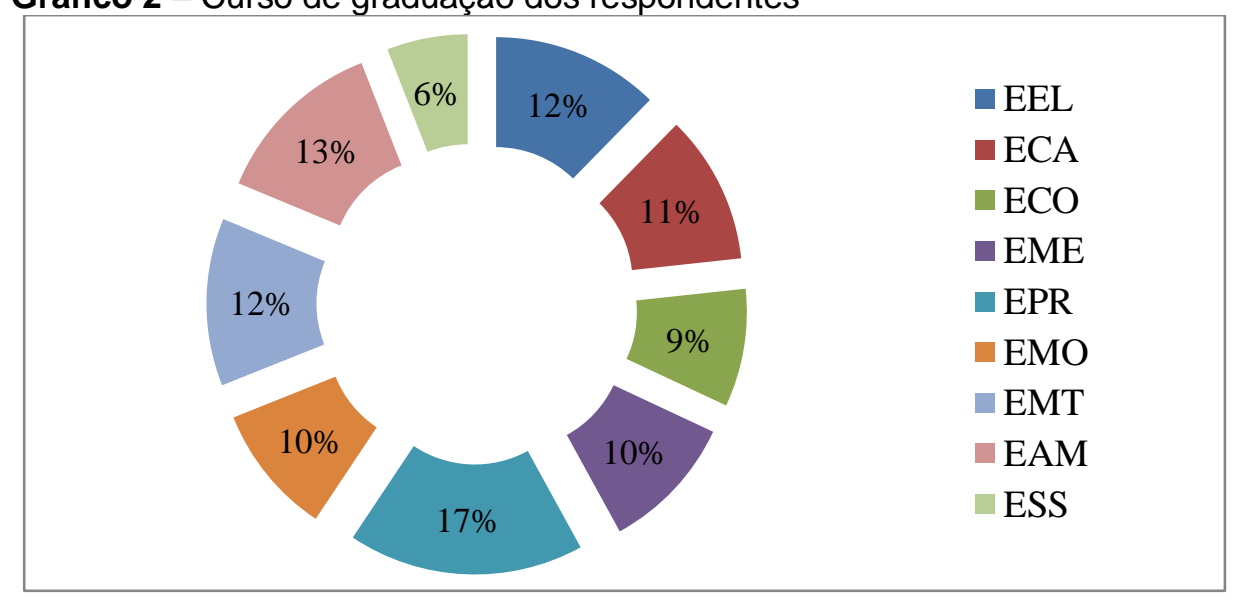

O Gráfico 3, por sua vez, apresenta a distribuição dos respondentes quanto ao tipo de instituição de ensino correspondente à maior parte do seu percurso educacional. Percebe-se que a maioria dos discentes entrevistados frequentou a rede pública de ensino (56\%).

Gráfico 3 - Percurso educacional dos respondentes

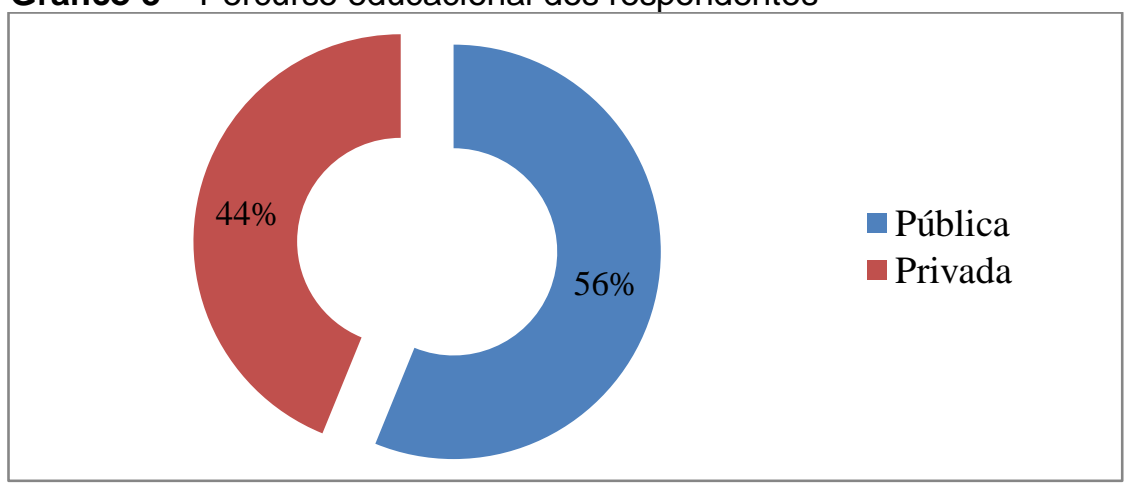

Revista Produção Online. Florianópolis, SC, v. 19, n. 2, p. 722-758, 2019. 
Outro aspecto analisado foi a faixa etária dos respondentes (Gráfico 4). A maior parte da faixa etária se concentra entre 22 e 25 anos (50\%). É importante ressaltar que nenhum dos entrevistados tem menos de 18 anos.

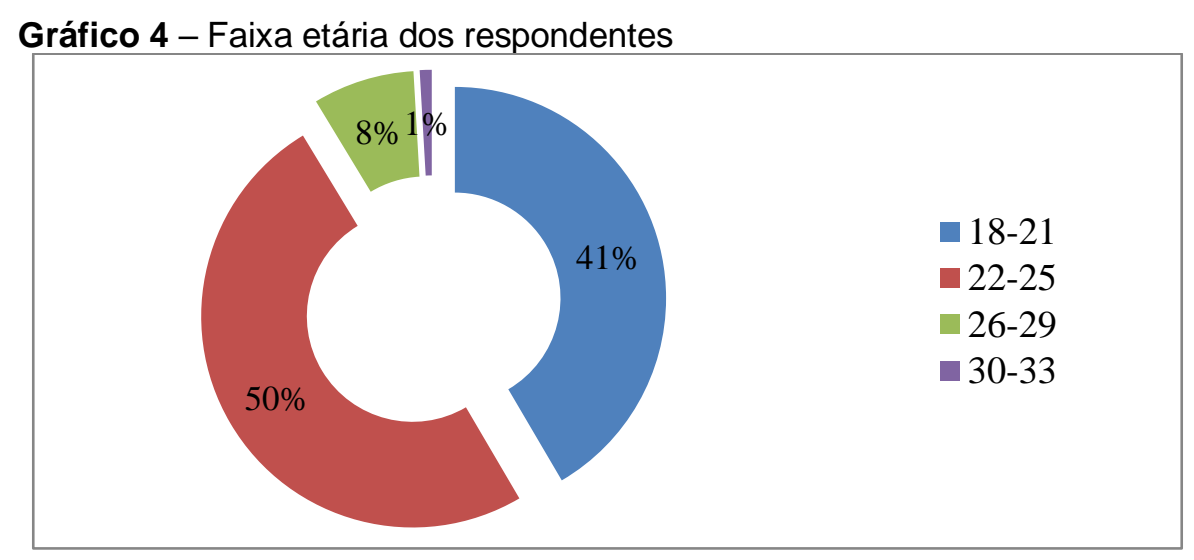

A partir da avaliação realizada pelos diferentes grupos de discentes, foi possível calcular as médias de cada setor, os Gaps de cada uma das 5 dimensões do serviço e ainda os desvios-padrão. Esses desvios correspondem à variabilidade amostral. Quanto menor o desvio-padrão maior a convergência entre as opiniões dos respondentes. Em uma análise geral, considerando os dados obtidos, percebe-se uma coerência entre as notas atribuídas pelos respondentes. Na Seção 4.9, foi realizado um teste de hipóteses (Teste t para 2 amostras) para comprovar estatisticamente a coerência dos respondentes com relação às avaliações realizadas.

\subsection{Análise dos resultados referentes aos serviços relacionados à Pesquisa}

A Tabela 2 apresenta os resultados obtidos a partir da análise dos 47 respondentes que avaliaram a prestação dos serviços relacionados à Pesquisa. 
Tabela 2 - Dimensões da qualidade e Gaps referentes aos serviços relacionados à Pesquisa

\begin{tabular}{|c|c|c|c|c|c|}
\hline \multirow[b]{3}{*}{ ITENS } & \multicolumn{2}{|c|}{ EXPECTATIVAS (E) } & \multicolumn{2}{|c|}{ PERCEPÇÕES (P) } & \multirow{2}{*}{$\begin{array}{l}\text { GAP } \\
\text { (P-E) }\end{array}$} \\
\hline & MÉDIA $(\bar{X})$ & $\begin{array}{c}\text { DESVIO } \\
\text { PADRÃO }(\sigma)\end{array}$ & MÉDIA $(\bar{X})$ & $\begin{array}{c}\text { DESVIO } \\
\text { PADRÃO }(\sigma)\end{array}$ & \\
\hline & \multicolumn{5}{|c|}{ TANGIBILIDADE } \\
\hline Equipamentos modernos & 4,6 & 0,7 & 4,4 & 0,8 & $-0,2$ \\
\hline Instalações físicas atraentes & 3,8 & 1 & 4,1 & 0,8 & 0,3 \\
\hline $\begin{array}{l}\text { Funcionários com boa } \\
\text { aparência }\end{array}$ & 3 & 1 & 3,8 & 0,9 & 0,8 \\
\hline Materiais atraentes & 3,9 & 1 & 3,5 & 1 & $-0,4$ \\
\hline \multicolumn{6}{|c|}{ CONFIABILIDADE } \\
\hline $\begin{array}{l}\text { Pontualidade de } \\
\text { serviços/entregas }\end{array}$ & 4,8 & 0,5 & 2,8 & 1 & -2 \\
\hline $\begin{array}{l}\text { Interesse em resolver } \\
\text { problemas }\end{array}$ & 4,7 & 0,5 & 3,0 & 1 & $-1,7$ \\
\hline $\begin{array}{l}\text { Realização do serviço certo } \\
\text { na primeira vez }\end{array}$ & 4,6 & 0,6 & 3,6 & 1,1 & -1 \\
\hline Cumprimento de prazos & 4,8 & 0,5 & 3,3 & 1 & $-1,5$ \\
\hline $\begin{array}{l}\text { Entregas e registros livres de } \\
\text { erros }\end{array}$ & 4,1 & 1 & 3,3 & 0,9 & $-0,8$ \\
\hline \multicolumn{6}{|c|}{ RESPONSIVIDADE } \\
\hline Estabelecimento de prazos & 4,4 & 0,9 & 3,2 & 1,1 & $-1,2$ \\
\hline Pronto atendimento & 4,4 & 0,7 & 3,1 & 1,1 & $-1,3$ \\
\hline Disposição para ajudar & 4,5 & 0,7 & 3,3 & 1,2 & $-1,2$ \\
\hline \multicolumn{6}{|c|}{ GARANTIA } \\
\hline Transmissão de confiança & 4,5 & 0,7 & 3,3 & 1 & $-1,2$ \\
\hline Segurança nas transações & 4,7 & 0,6 & 2,8 & 1,1 & $-1,9$ \\
\hline Cortesia no relacionamento & 4,2 & 0,9 & 3,5 & 1,1 & $-0,7$ \\
\hline $\begin{array}{l}\text { Conhecimento para responder } \\
\text { questionamentos }\end{array}$ & 4,3 & 0,6 & 3,4 & 1 & $-0,9$ \\
\hline \multicolumn{6}{|c|}{ EMPATIA } \\
\hline Atenção individualizada & 3,3 & 1 & 2,9 & 1,1 & $-0,4$ \\
\hline $\begin{array}{l}\text { Horários de funcionamento } \\
\text { convenientes }\end{array}$ & 4,2 & 0,9 & 2,8 & 1,2 & $-1,4$ \\
\hline Atendimento personalizado & 2,8 & 1 & 2,7 & 1,1 & $-0,1$ \\
\hline Interesse genuíno em clientes & 4,3 & 1 & 3,3 & 0,9 & -1 \\
\hline $\begin{array}{l}\text { Entendimento de } \\
\text { necessidades específicas }\end{array}$ & 3,8 & 0,9 & 3 & 0,9 & $-0,8$ \\
\hline
\end{tabular}

No setor de Pesquisa, dos 22 itens propostos pelo questionário ServQual apenas 2 possuem Gaps positivos, ou seja, nesses itens a instituição supera as expectativas dos discentes. Os demais itens (20) correspondem àqueles em que as expectativas dos discentes não foram atingidas. Destacam-se como pontos positivos os itens relacionados à Tangibilidade, são eles: "Instalações físicas atraentes" com Gap 0,3 e "Funcionários com boa aparência" com Gap 0,8.

Dentre os itens que apresentaram Gap negativo, destacaram-se "Pontualidade de serviços/entregas" (Confiabilidade) com Gap -2, seguido por "Segurança nas transações" (Garantia) com Gap -1,9 e "Interesse em resolver problemas" 
(Confiabilidade) com Gap -1,7. O Gráfico 5 apresenta a média final das percepções e expectativas, além do Gap calculado para cada uma das 5 dimensões avaliadas pelo questionário ServQual.

Gráfico 5 - Percepção e Expectativa dos discentes com relação aos serviços relacionados à Pesquisa

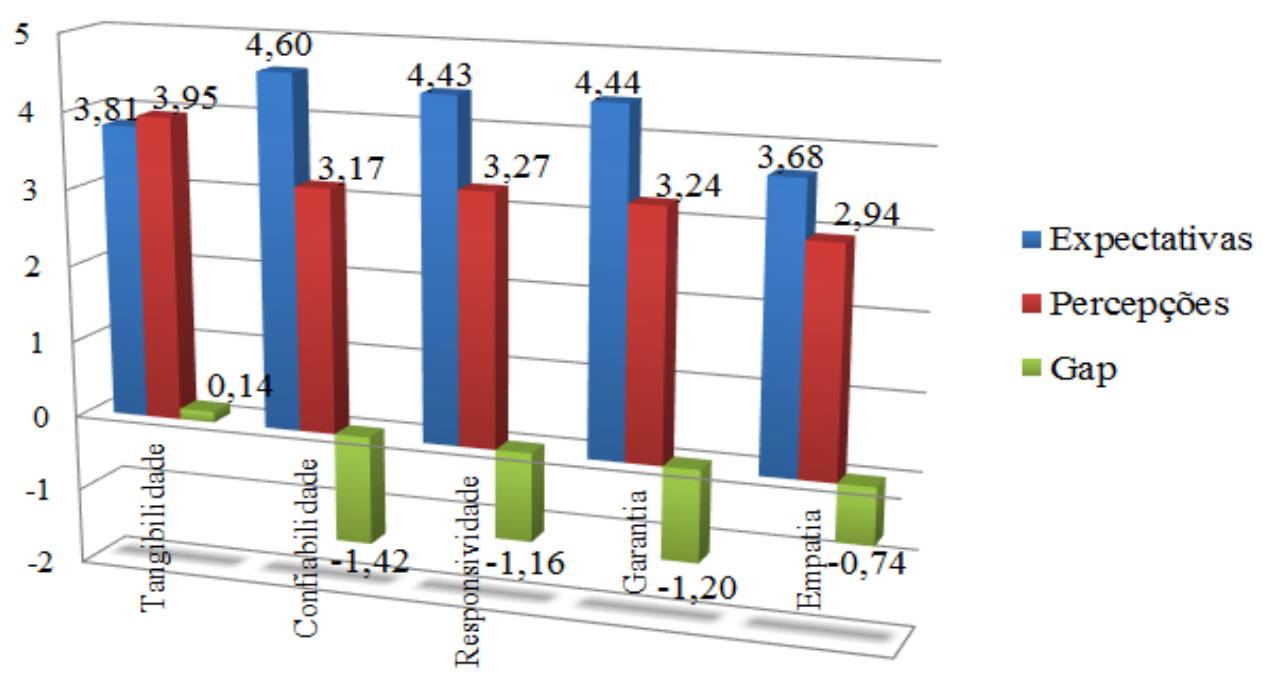

Os resultados permitem identificar que a dimensão Tangibilidade é a única que apresenta um Gap positivo $(0,14)$ e que o Gap mais significativo corresponde à dimensão Confiabilidade $(-1,42)$.

Os discentes que avaliaram os serviços relacionados à Pesquisa apontaram como ponto forte da instituição a infraestrutura dos laboratórios, o que está coerente com média final do Gap correspondente ao item Tangibilidade. As oportunidades de melhoria mais citadas encontram-se classificadas no Gráfico 6.

Gráfico 6 - Oportunidades de melhoria mais citadas para a prestação de serviços relacionados à Pesquisa

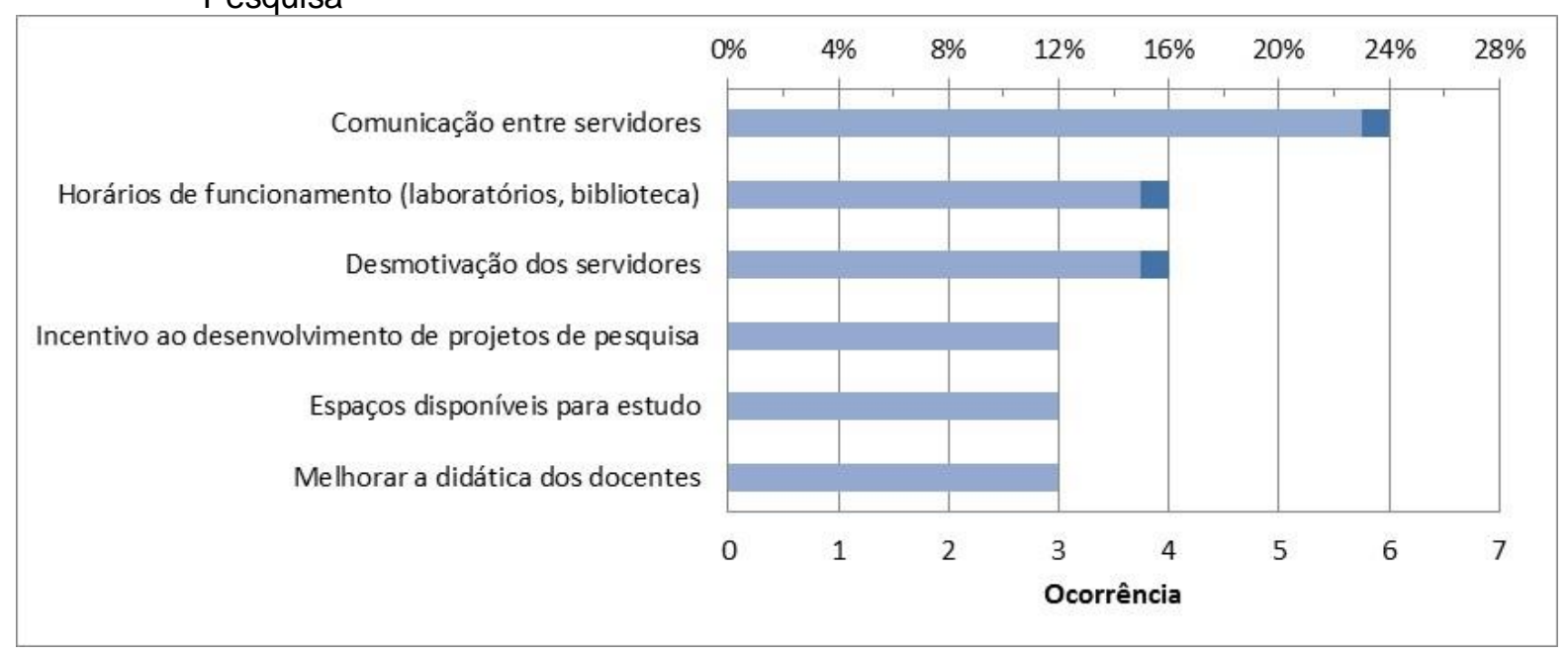


As oportunidades de melhoria mais citadas e comentadas pelos alunos foram (Gráfico 6):

(1) comunicação entre funcionários de um mesmo setor: segundo os alunos, servidores de um mesmo setor apresentam informações contraditórias quanto a um procedimento/solicitação. Comentaram que essas informações também divergem entre os diferentes setores da Universidade.

(2) o horário de funcionamento dos laboratórios e da biblioteca: as disciplinas são ministradas entre $7 \mathrm{~h}$ e $22 \mathrm{~h}$, entretanto a estrutura da Universidade não segue esse horário de funcionamento. Como os horários do transporte público são limitados, muitos estudantes optam por ficar no Câmpus durante todo o dia. O Câmpus, por sua vez, não possui muitos espaços disponíveis para estudo e, além disso, a biblioteca e os laboratórios têm o horário de funcionamento reduzidos, impossibilitando que desenvolvam atividades de pesquisa no seu tempo livre.

(3) desmotivação de alguns dos servidores da instituição: os alunos relataram que é perceptível a desmotivação de alguns dos servidores. Citaram como exemplos $\mathrm{o}$ atendimento prestado e a alta rotatividade dos docentes (turnover).

(4) incentivo para o desenvolvimento de pesquisas: os discentes relataram que as bolsas ofertadas não são suficientes para o número de alunos que buscam desenvolver projetos de pesquisa e, além disso, a situação de alguns laboratórios prejudicam o desenvolvimento de pesquisas, por falta de manutenção, de reagentes, horário de funcionamento, etc.

Os espaços disponíveis para estudos e a didática dos docentes também foram citadas como oportunidades de melhoria, mas não foram realizados comentários sobre cada item. As oportunidades de melhoria citadas fazem conexão com os Gaps negativos identificados.

\subsection{Análise dos resultados referentes aos serviços relacionados ao Ensino}

A Tabela 3 corresponde aos resultados obtidos a partir da análise dos 88 respondentes referente à qualidade da prestação dos serviços relacionados ao Ensino.

Pode-se inferir, a partir dos dados apresentados na Tabela 3, que o aspecto Tangibilidade ainda é o melhor avaliado dentre os discentes. Destaca-se como ponto 
forte o item "Funcionários com boa aparência" com Gap 0,3 e, nesse caso, o item "Instalações físicas atraentes", as percepções dos discentes são iguais às suas expectativas, resultando em um Gap nulo. Para os serviços relacionados ao Ensino, os discentes destacaram como pontos fortes da instituição as numerosas oportunidades de projetos de extensão (que permitem aplicar conceitos repassados nas disciplinas), a disponibilidade dos docentes, além da infraestrutura dos laboratórios.

Considerando os que apresentaram Gap negativo, destacam-se os itens "Pontualidade de serviços/entregas" (Confiabilidade) com Gap -2,1 e "Segurança nas transações" (Garantia) com Gap -1,8.

Tabela 3 - Dimensões da qualidade e Gaps com relação aos serviços relacionados ao Ensino

\begin{tabular}{|c|c|c|c|c|c|}
\hline & MÉDIA $(\bar{X})$ & $\begin{array}{c}\text { DESVIO } \\
\text { PADRÃO }(\sigma)\end{array}$ & MÉDIA $(\bar{X})$ & $\begin{array}{c}\text { DESVIO } \\
\operatorname{PADRÃO}(\sigma)\end{array}$ & $\begin{array}{l}\text { GAP } \\
\text { (P-E) }\end{array}$ \\
\hline ITENS & \multicolumn{5}{|c|}{ TANGIBILIDADE } \\
\hline Equipamentos modernos & 4,7 & 0,6 & 4,4 & 0,7 & $-0,3$ \\
\hline Instalações físicas atraentes & 3,8 & 0,8 & 3,8 & 1 & 0 \\
\hline $\begin{array}{l}\text { Funcionários com boa } \\
\text { aparência }\end{array}$ & 3,3 & 1 & 3,6 & 0,8 & 0,3 \\
\hline Materiais atraentes & \multicolumn{5}{|c|}{ CONFIABILIDADE } \\
\hline $\begin{array}{l}\text { Pontualidade de } \\
\text { serviços/entregas }\end{array}$ & 4,8 & 0,6 & 2,7 & 0,9 & $-2,1$ \\
\hline $\begin{array}{l}\text { Interesse em resolver } \\
\text { problemas }\end{array}$ & 4,7 & 0,6 & 3,1 & 0,9 & -1.6 \\
\hline $\begin{array}{l}\text { Realização do serviço certo na } \\
\text { primeira vez }\end{array}$ & 4,5 & 0,7 & 3,5 & 1 & -1 \\
\hline Cumprimento de prazos & 4,7 & 0,6 & 3,1 & 1 & $-1,6$ \\
\hline $\begin{array}{l}\text { Entregas e registros livres de } \\
\text { erros }\end{array}$ & 4,3 & 0,8 & 3,3 & 0,9 & -1 \\
\hline & \multicolumn{5}{|c|}{ RESPONSIVIDADE } \\
\hline Estabelecimento de prazos & 4,6 & 0,6 & 3,1 & 1,1 & $-1,5$ \\
\hline Pronto atendimento & 4,4 & 0,7 & 3,2 & 1 & $-1,2$ \\
\hline Disposição para ajudar & 4,6 & 0,7 & 3,1 & 1 & $-1,5$ \\
\hline Resposta ágil nas solicitações & \multicolumn{4}{|c|}{ GARANTIA } & -1 \\
\hline Transmissão de confiança & 4,5 & 0,7 & 3,2 & 0,9 & $-1,3$ \\
\hline Segurança nas transações & 4,7 & 0,7 & 2,9 & 1 & $-1,8$ \\
\hline Cortesia no relacionamento & 4,3 & 0,8 & 3,2 & 1,1 & $-1,1$ \\
\hline $\begin{array}{l}\text { Conhecimento para responder } \\
\text { questionamentos }\end{array}$ & 4,3 & 0,6 & 3,4 & 0,9 & $-0,9$ \\
\hline & \multicolumn{5}{|c|}{ CONFIABILIDADE } \\
\hline Atenção individualizada & 3,6 & 0,9 & 2,8 & 1 & $-0,8$ \\
\hline $\begin{array}{l}\text { Horários de funcionamento } \\
\text { convenientes }\end{array}$ & 4,3 & 0,8 & 2,8 & 1,1 & $-1,5$ \\
\hline Atendimento personalizado & 3,3 & 1 & 2,5 & 1 & $-0,8$ \\
\hline Interesse genuíno em clientes & 4,5 & 0,8 & 3,2 & 1 & $-1,3$ \\
\hline $\begin{array}{l}\text { Entendimento de necessidades } \\
\text { específicas }\end{array}$ & 4,2 & 0,8 & 2,9 & 1 & $-1,3$ \\
\hline
\end{tabular}


O Gráfico 7 apresenta os resultados obtidos da média das percepções e expectativas do setor de Ensino, bem como o Gap para cada uma das cinco dimensões analisadas.

Gráfico 7 - Percepção e Expectativa dos discentes com relação aos serviços relacionados ao Ensino

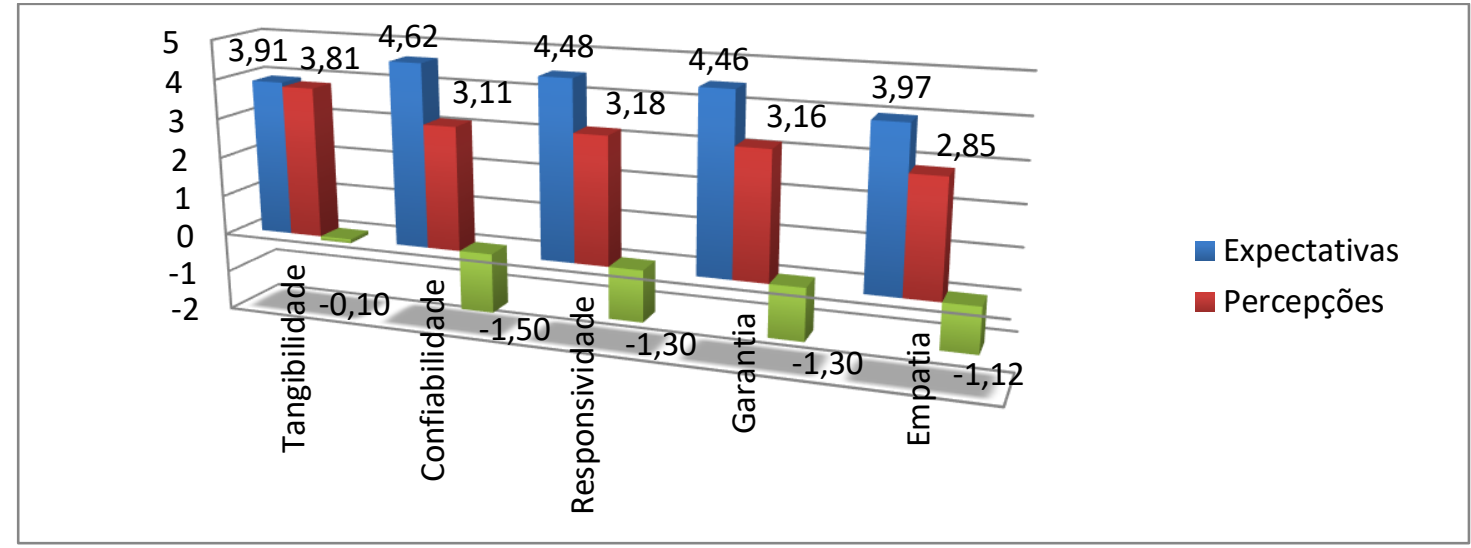

Ao contrário dos demais setores avaliados, a dimensão Tangibilidade apresenta um Gap negativo $(-0,1)$. Além disso, verifica-se que o Gap mais relevante está relacionado à dimensão Confiabilidade $(-1,5)$. Os discentes apontaram como oportunidades de melhoria no setor os itens classificados no Gráfico 8.

Gráfico 8 - Oportunidades de melhoria mais citadas para a prestação de serviços relacionados ao Ensino

\begin{tabular}{|r|r|r|r|r|r|}
\hline \multicolumn{2}{|c|}{$0 \%$} & & \\
Divulgação de prazos, procedimentos e eventos \\
Melhorar a didática dos docentes
\end{tabular}

As principais oportunidades de melhoria apontadas por esse grupo de discentes são (Gráfico 8):

(1) A divulgação de prazos, procedimentos e eventos que ocorrem dentro da 
instituição: os discentes relataram que os prazos não são muito bem divulgados ou até mesmo desconhecidos, como o lançamento de notas, solicitação de revisão de provas, bem como o procedimento para a realização de algumas solicitações.

(2) A melhoria da didática dos docentes: muitos docentes tratam todos os alunos da mesma maneira, sem considerar que alguns apresentam maior domínio sobre um assunto e outros não. Além disso, não existe uma ferramenta eficiente para avaliar a didática do docente.

(3) Novamente, o horário de funcionamento dos laboratórios e da biblioteca e

(4) Desmotivação de alguns dos servidores para a realização das suas atividades.

(5) Também foi citada a relação entre Coordenadores de Curso e os discentes: relataram que a relação entre alguns coordenadores e discentes é frágil. Reuniões periódicas para avaliação e discussão de temas importantes para os cursos deveriam ser agendadas para melhorar essa relação.

Essas observações estão alinhadas aos Gaps negativos apresentados.

\subsection{Análise dos resultados referentes aos serviços relacionados à Extensão}

A Tabela 4 apresenta a média e o desvio padrão de cada item, bem como o Gap existente entre as expectativas e percepções considerando os 52 discentes que avaliaram a qualidade dos serviços relacionados à Extensão.

Assim como para Pesquisa e Ensino, os itens relacionados à dimensão Tangibilidade apresentaram Gaps positivos referentes aos serviços relacionados à Extensão, são eles: "Instalações físicas atraentes" com Gap 0,1 e "Funcionários com boa aparência" com Gap 0,5. Os discentes desse grupo reforçaram a satisfação com relação à estrutura dos laboratórios e destacaram ainda os benefícios trazidos pela proximidade entre alunos e professores, o que contribui com o desenvolvimento dos projetos de extensão. Entre os 20 itens com Gaps negativos nesse serviço, os itens "Segurança nas transações" (Garantia) com Gap -2,1, "Pontualidade de serviços/entregas" (Confiabilidade) com Gap -2,1 e "Interesse em resolver problemas" (Confiabilidade) com Gap -1,7 também se destacaram. O Gráfico 9 apresenta a média final das expectativas, além do Gap calculado entre os discentes que avaliaram o setor 
de Extensão.

Tabela 4 - Dimensões da qualidade e Gaps para os serviços relacionados à Extensão

\begin{tabular}{|c|c|c|c|c|c|}
\hline & $\begin{array}{l}\text { MÉDIA } \\
(\bar{X})\end{array}$ & $\begin{array}{c}\text { DESVIO } \\
\text { PADRÃO }(\sigma)\end{array}$ & $\begin{array}{c}\text { MÉDIA } \\
(\bar{X})\end{array}$ & $\begin{array}{c}\text { DESVIO } \\
\text { PADRÃO }(\sigma)\end{array}$ & $\begin{array}{l}\text { GAP } \\
\text { (P-E) }\end{array}$ \\
\hline ITENS & \multicolumn{5}{|c|}{ TANGIBILIDADE } \\
\hline Equipamentos modernos & 4,7 & 0,6 & 4,5 & 0,7 & $-0,2$ \\
\hline Instalacões físicas atraentes & 3,8 & 0,9 & 3,9 & 0,8 & 0,1 \\
\hline Funcionários com boa aparência & 3,1 & 1,1 & 3,6 & 0,7 & 0,5 \\
\hline Materiais atraentes & 3,8 & 0,9 & 3,4 & 0,8 & $-0,4$ \\
\hline Pontualidade de & & \multicolumn{3}{|c|}{ CONFIABILIDADE } & \\
\hline serviços/entregas & 4,8 & 0,4 & 2,7 & 0,8 & $-2,1$ \\
\hline Interesse em resolver problemas & 4,6 & 0,7 & 2,9 & 0,9 & $-1,7$ \\
\hline $\begin{array}{l}\text { Realização do serviço certo na } \\
\text { primeira vez }\end{array}$ & 4,4 & 0,7 & 3,1 & 1,1 & $-1,3$ \\
\hline Cumprimento de prazos & 4,7 & 0,4 & 3,1 & 1 & $-1,6$ \\
\hline $\begin{array}{l}\text { Entregas e registros livres de } \\
\text { erros }\end{array}$ & 4,5 & 0,8 & 3,2 & 0,9 & $-1,3$ \\
\hline & \multicolumn{5}{|c|}{ RESPONSIVIDADE } \\
\hline Estabelecimento de prazos & 4,6 & 0,6 & 3,1 & 1,1 & $-1,5$ \\
\hline Pronto atendimento & 4,6 & 0,5 & 3,2 & 1 & $-1,4$ \\
\hline Disposição para ajudar & 4,6 & 0,6 & 3,3 & 0,8 & $-1,3$ \\
\hline Resposta ágil nas solicitações & 4,6 & 0,7 & $\begin{array}{c}3,4 \\
\text { ARANTIA }\end{array}$ & 0,9 & $-1,2$ \\
\hline Transmissão de confiança & 4,5 & 0,7 & 3,2 & 0,9 & $-1,3$ \\
\hline Segurança nas transações & 4,8 & 0,5 & 2,7 & 1,1 & $-2,1$ \\
\hline Cortesia no relacionamento & 4,5 & 0,7 & 3,2 & 0,9 & $-1,3$ \\
\hline $\begin{array}{l}\text { Conhecimento para responder } \\
\text { questionamentos }\end{array}$ & 4,3 & 0,7 & 3,3 & 0,9 & -1 \\
\hline \multirow{3}{*}{$\begin{array}{l}\text { Atenção individualizada } \\
\text { Horários de funcionamento } \\
\text { convenientes }\end{array}$} & \multicolumn{5}{|c|}{ EMPATIA } \\
\hline & 3,6 & 1 & 2,8 & 0,9 & $-0,8$ \\
\hline & 4,4 & 0,8 & 2,9 & 1,3 & $-1,5$ \\
\hline Atendimento personalizado & 3,4 & 1,1 & 2,5 & 0,9 & $-0,9$ \\
\hline Interesse genuíno em clientes & 4,6 & 0,7 & 3,2 & 0,9 & $-1,4$ \\
\hline $\begin{array}{l}\text { Entendimento de necessidades } \\
\text { específicas }\end{array}$ & 4,2 & 1 & 2,9 & 1 & $-1,3$ \\
\hline
\end{tabular}

Gráfico 9 - Percepção e Expectativa dos discentes com relação aos serviços relacionados à Extensão

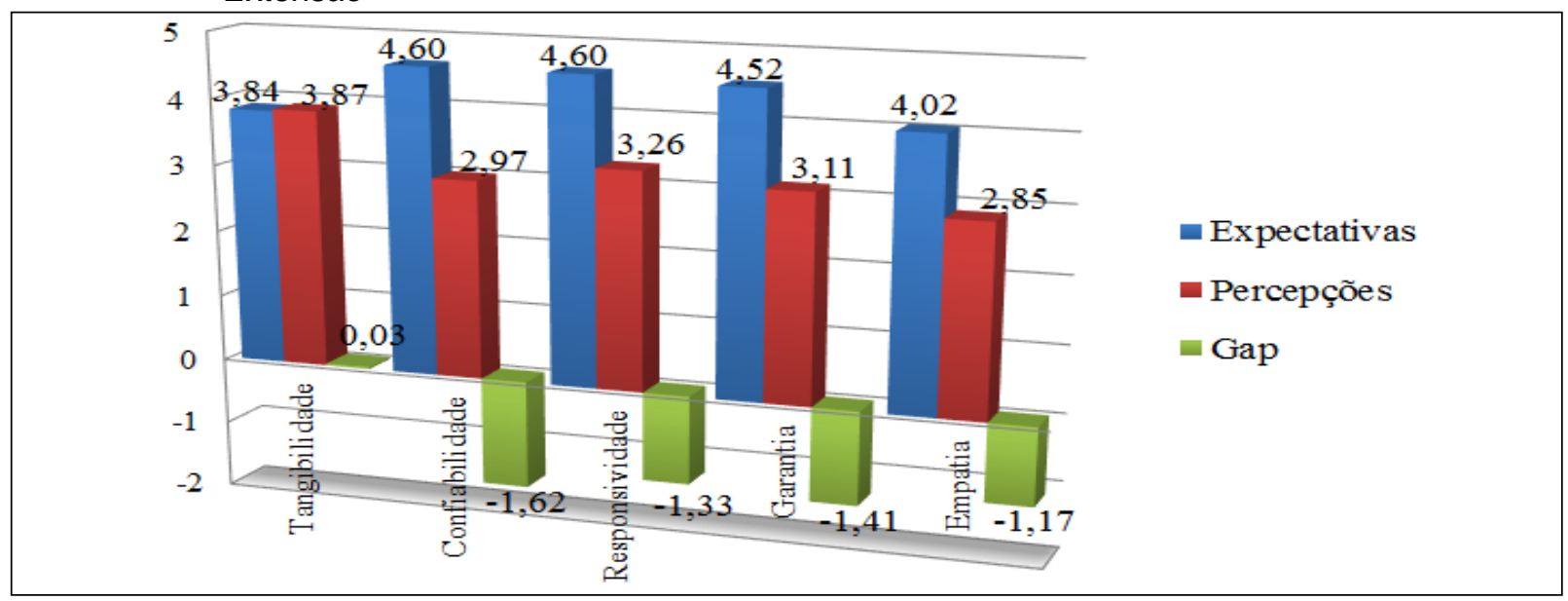


A partir dos dados apresentados no Gráfico 9, é possível verificar que a dimensão Tangibilidade é a única que apresenta um Gap positivo $(0,03)$, e que o Gap correspondente à dimensão Confiabilidade $(-1,62)$ é o mais relevante.

Os discentes apontaram como oportunidades de melhoria os itens apresentados no Gráfico 10.

Gráfico 10 - Oportunidades de melhoria mais citadas para a prestação de serviços relacionados à Extensão

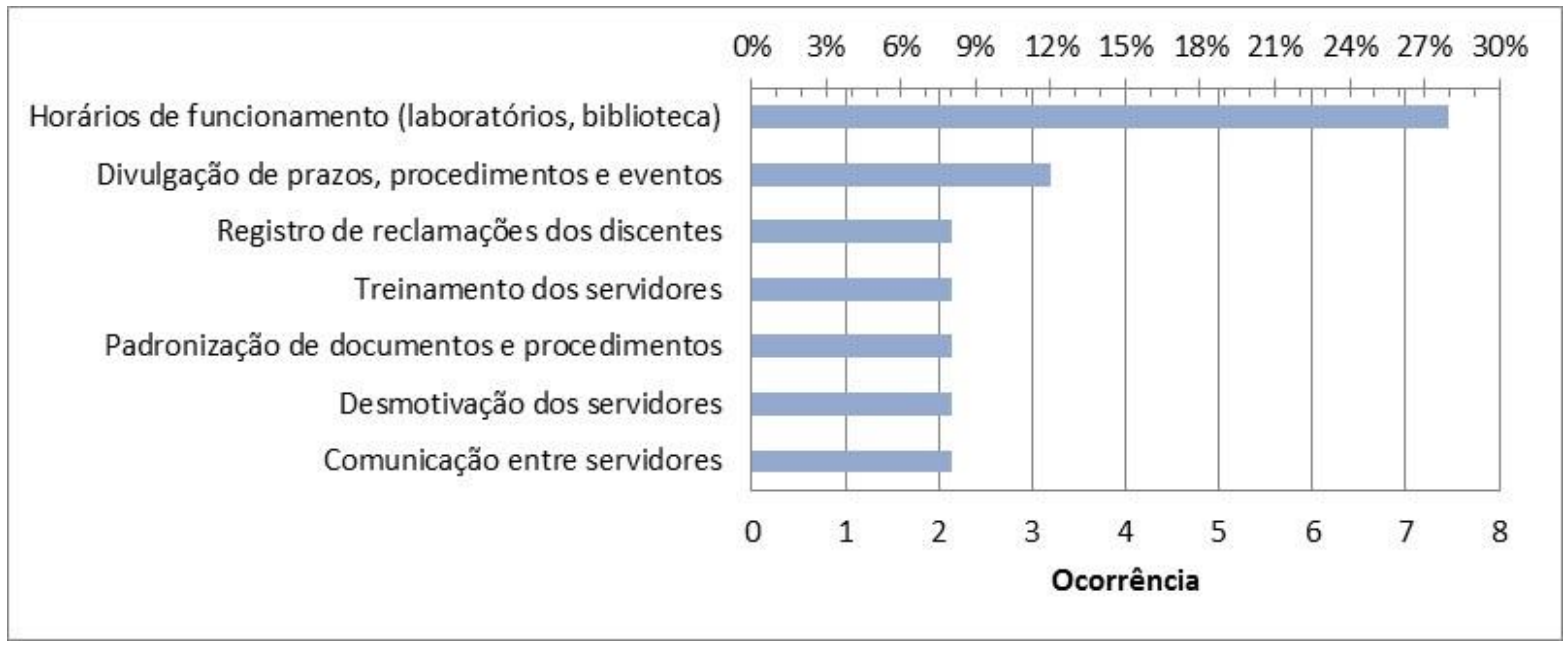

Os discentes reforçaram a necessidade de melhorias com relação a:

(1) Horário de funcionamento dos laboratórios e da biblioteca e destacaram, mais uma vez, (2) a divulgação de prazos, procedimentos e eventos da instituição, sugestões que exemplificam e reforçam os Gaps negativos identificados.

\subsection{Análise dos resultados referentes aos Serviços Administrativos}

A Tabela 5 contempla os resultados obtidos considerando os 32 discentes que avaliaram os Serviços Administrativos da instituição. 
Tabela 5 - Dimensões da qualidade e Gaps com relação aos Serviços Administrativos

\begin{tabular}{|c|c|c|c|c|c|}
\hline & MÉDIA $(\bar{X})$ & $\begin{array}{c}\text { DESVIO } \\
\text { PADRÃO }(\sigma)\end{array}$ & MÉDIA $(\bar{X})$ & $\begin{array}{c}\text { DESVIO } \\
\text { PADRÃO }(\sigma)\end{array}$ & $\begin{array}{l}\text { GAP } \\
\text { (P-E) }\end{array}$ \\
\hline ITENS & \multicolumn{5}{|c|}{ TANGIBILIDADE } \\
\hline Equipamentos modernos & 4,7 & 0,5 & 4,6 & 0,6 & $-0,1$ \\
\hline Instalações físicas atraentes & 3,6 & 1 & 4,3 & 0,7 & 0,7 \\
\hline $\begin{array}{l}\text { Funcionários com boa } \\
\text { aparência }\end{array}$ & 3,6 & 0,9 & 4 & 0,7 & 0,4 \\
\hline Materiais atraentes & 3,9 & 0,9 & 3,8 & 0,9 & $-0,1$ \\
\hline \multirow{2}{*}{$\begin{array}{l}\text { Interesse em resolver } \\
\text { problemas }\end{array}$} & 5 & 0 & 3 & 0,9 & -2 \\
\hline & \multicolumn{5}{|c|}{ CONFIABILIDADE } \\
\hline $\begin{array}{l}\text { Pontualidade de } \\
\text { serviços/entregas }\end{array}$ & 4,9 & 0,2 & 2,5 & 1 & $-2,4$ \\
\hline $\begin{array}{l}\text { Interesse em resolver } \\
\text { problemas }\end{array}$ & 5 & 0 & 3 & 0,9 & -2 \\
\hline $\begin{array}{l}\text { Realização do serviço certo na } \\
\text { primeira vez }\end{array}$ & 4,5 & 0,8 & 3,3 & 1,2 & $-1,2$ \\
\hline Cumprimento de prazos & 4,9 & 0,3 & 3 & 1,1 & $-1,9$ \\
\hline \multirow{2}{*}{$\begin{array}{l}\text { Entregas e registros livres de } \\
\text { erros }\end{array}$} & 4,5 & 0,8 & 3,3 & 0,9 & $-1,2$ \\
\hline & \multicolumn{5}{|c|}{ RESPONSIVIDADE } \\
\hline Estabelecimento de prazos & 4,6 & 0,6 & 3,1 & 1,3 & $-1,5$ \\
\hline Pronto atendimento & 4.6 & 0.5 & 3 & 1,1 & $-1,6$ \\
\hline Disposição para ajudar & 4,8 & 0,5 & 3,1 & 0,9 & $-1,7$ \\
\hline Resposta ágil nas solicitações & 4,7 & 0,5 & $\begin{array}{l}3,3 \\
3\end{array}$ & 1 & $-1,4$ \\
\hline Transmissão de confiança & 4,8 & 0,5 & 3 & 1 & $-1,8$ \\
\hline Sequranca nas transacões & 4.8 & 0.5 & 24 & 12 & -2.4 \\
\hline \multirow{3}{*}{$\begin{array}{l}\text { Cortesia no relacionamento } \\
\text { Conhecimento para responder } \\
\text { questionamentos }\end{array}$} & 4,6 & 0,5 & 3,3 & $\begin{array}{l}1, c \\
1,1\end{array}$ & $-1,3$ \\
\hline & 4,4 & 0,7 & 3,2 & 1,1 & $-1,2$ \\
\hline & \multicolumn{5}{|c|}{ EMPATIA } \\
\hline \multirow{4}{*}{$\begin{array}{l}\text { Atenção individualizada } \\
\text { Horários de funcionamento } \\
\text { convenientes } \\
\text { Atendimento personalizado } \\
\text { Interesse genuíno em clientes } \\
\text { Entendimento de necessidades } \\
\text { específicas }\end{array}$} & 3,7 & 1 & 2,7 & 1 & -1 \\
\hline & 4,7 & 0,5 & 2,9 & 1,2 & $-1,8$ \\
\hline & $\begin{array}{l}3,3 \\
4,6\end{array}$ & $\begin{array}{l}1,1 \\
0,6\end{array}$ & $\begin{array}{l}2,8 \\
3,3\end{array}$ & $\begin{array}{l}1 \\
1\end{array}$ & $\begin{array}{l}-0,5 \\
-1,3\end{array}$ \\
\hline & 4,3 & 0,9 & 2,8 & 1,1 & $-1,5$ \\
\hline
\end{tabular}

O resultado da análise feita pelos discentes do grupo relacionado a Serviços Administrativos reforça, mais uma vez, que o aspecto Tangibilidade se destaca entre os demais avaliados. Como pontos fortes, os itens que apresentam Gap positivo são: "Instalações físicas atraentes" $(0,7)$ e "Funcionários com boa aparência" $(0,4)$. Nesse caso, os discentes destacaram como pontos fortes o novo sistema implementado, o Sistema Integrado de Gestão de Atividades Acadêmicas (SIGAA), por ter simplificado alguns procedimentos anteriormente muito burocráticos, os projetos de extensão desenvolvidos (incluindo cursos, seminários, etc.), que favorecem um desenvolvimento mais completo ao aluno, a divisão dos setores da instituição, que simplifica a realização e distribuição de tarefas e ainda a qualidade dos laboratórios. 
Com relação aos pontos a serem melhorados, destacam-se os itens "Pontualidade de serviços/entregas" (Confiabilidade) com Gap -2,4, "Segurança nas transações" (Garantia) com Gap -2,4 e "Interesse em resolver problemas" (Confiabilidade) com Gap -2.

O Gráfico 11 contempla os resultados obtidos para cada uma das 5 dimensões avaliadas no questionário ServQual.

Gráfico 11 - Percepção e Expectativa dos discentes com relação aos Serviços Administrativos

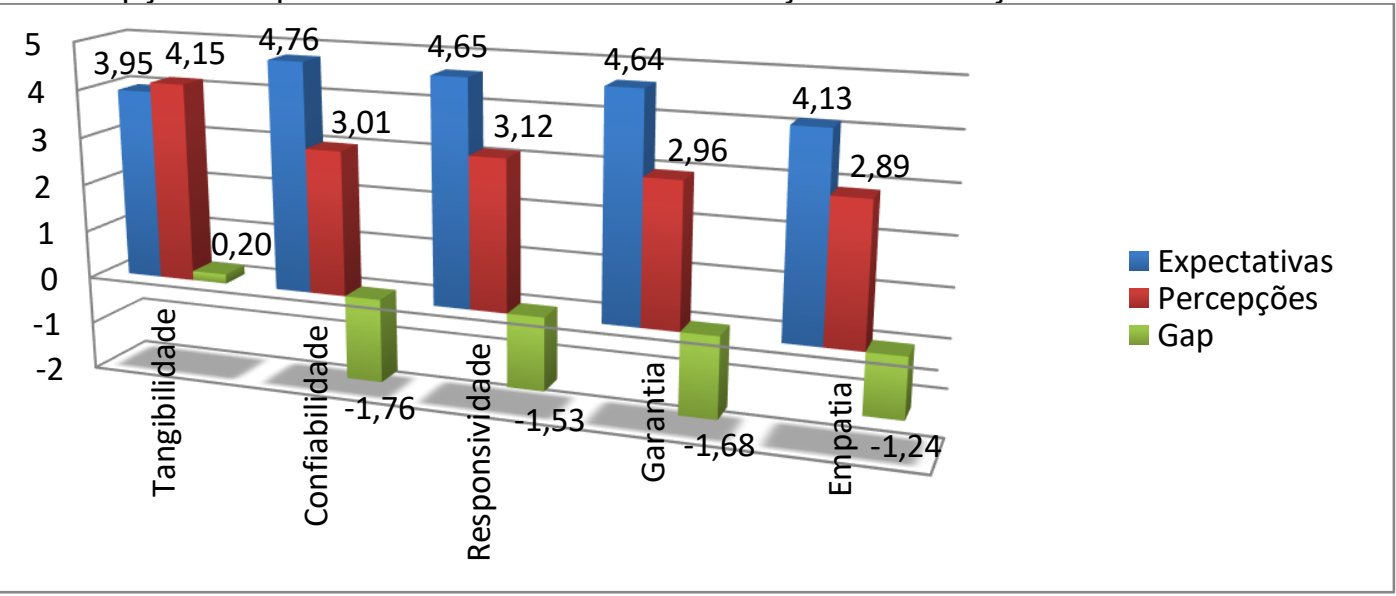

A dimensão Tangibilidade, assim como nos demais grupos, é a única a apresentar um Gap positivo $(0,20)$, sendo que o Gap correspondente à dimensão Confiabilidade $(-1,76)$ se apresenta como um ponto importante a ser considerado pelos gestores. As principais oportunidades de melhorias identificadas por esse grupo de respondentes podem ser observadas no Gráfico 12.

Gráfico 12 - Oportunidades de melhoria mais citadas relacionadas à prestação de Serviços Administrativos

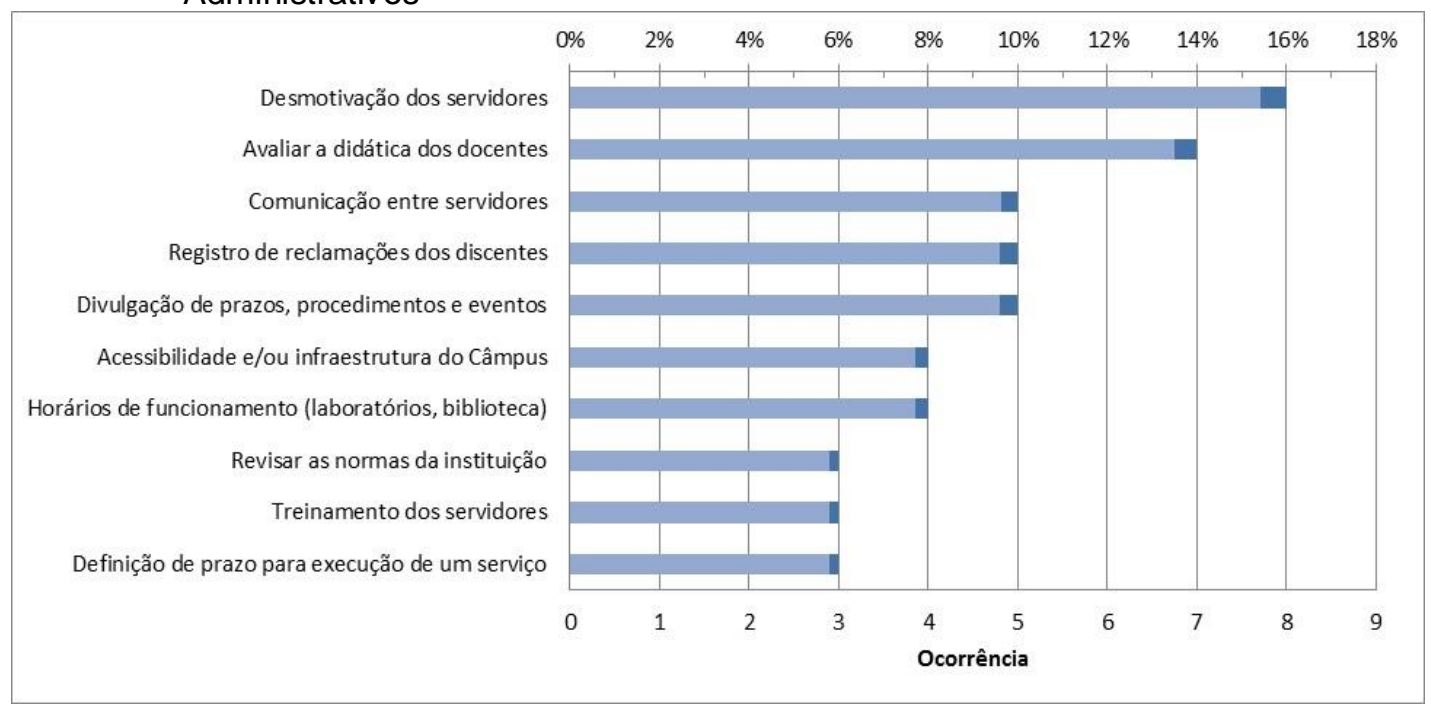


Os discentes apontaram como principais pontos negativos:

(1) A desmotivação de alguns servidores para a realização das suas atividades.

(2) A necessidade de avaliação da metodologia e didática de alguns docentes: questionaram a eficiência das ferramentas já existentes para avaliar a didática dos docentes. Para eles, é muito importante que os alunos avaliem semestralmente o modelo de trabalho dos professores, a fim de aprimorar o desenvolvimento dos cursos e do aprendizado dos alunos.

(3) A comunicação entre funcionários de um mesmo setor e de diferentes setores.

(4) Um modelo eficaz de registro de reclamações dos discentes: relataram que muitos alunos se sentem desmotivados a realizar reclamações formais na instituição, uma vez que os resultados das mesmas não são divulgados.

(5) Além da divulgação de prazos, procedimentos e eventos na instituição avaliada.

Essas observações justificam os Gaps negativos identificados.

\subsection{Cálculos do Coeficiente Alfa de Cronbach}

No intuito de verificar a confiabilidade do questionário, o coeficiente Alfa de Cronbach foi calculado para os diferentes grupos de respondentes utilizando-se o software Excel. Hora, Monteiro e Arica (2010) afirmam que é possível estimar a confiabilidade de um instrumento de coleta de dados por meio da correlação média entre as respostas, e é nesse princípio que se baseia o cálculo desse coeficiente (Equação 3).

$$
\alpha=\left(\frac{k}{k-1}\right) \times\left(1-\frac{\sum_{i=1}^{k} S_{i}^{2}}{S_{t}^{2}}\right)
$$

Em que $\mathrm{k}$ corresponde ao número de itens do questionário, $\mathrm{s}_{\mathrm{i}}^{2}$ à variância de cada item $i$ e $s_{\mathrm{t}}^{2}$ corresponde à variância total do questionário, determinada como a soma de todas as variâncias.

O coeficiente Alfa de Cronbach foi então calculado para as expectativas e percepções de cada um dos quatro setores analisados, conforme demonstrado na Tabela 6. 
Tabela 6 - Coeficientes Alfa de Cronbach para cada segmento

\begin{tabular}{lcc}
\hline \multicolumn{1}{c}{ SETOR } & EXPECTATIVAS $(\boldsymbol{\alpha})$ & PERCEPÇÕES $(\boldsymbol{\alpha})$ \\
\hline Pesquisa & 0,85 & 0,93 \\
Ensino & 0,89 & 0,93 \\
Extensão & 0,88 & 0,89 \\
Serviços Administrativos & 0,84 & 0,90 \\
\hline
\end{tabular}

Embora não exista um consenso entre pesquisadores, Freitas e Rodrigues (2005) afirmam que o coeficiente pode ser considerado satisfatório quando assume um valor igual ou superior a 0,7. Dessa forma, como pode ser observado na Tabela 6 , pode-se confirmar a confiabilidade das avaliações.

\subsection{Teste de Aderência}

Para confirmar se os dados seguem uma distribuição normal, foi realizada a análise da normalidade utilizando-se o teste estatístico de Anderson-Darling (AD). As Tabelas 7 a 10 apresentam os resultados obtidos. O tamanho da amostra (N) é representado pelo curso de graduação dos respondentes da pesquisa (Figura 2), sendo o nível de significância de $5 \%(\alpha=0,05)$.

Tabela 7 - Teste de aderência para as atividades relacionadas à Pesquisa Valores esperados (expectativa)

\begin{tabular}{|c|c|c|c|c|c|c|c|}
\hline Dimensão & Média $(\mu)$ & $\begin{array}{c}\text { Desvio } \\
\text { Padrão }(\sigma)\end{array}$ & $\mathbf{N}$ & Valor AD & Valor_P & Decisão & Conclusão \\
\hline Tangibilidade & 3,847 & 0,221 & 9 & 0,174 & 0,895 & Aceito $\mathrm{H}_{0}$ & $\begin{array}{l}\text { Os dados se } \\
\text { distribuiçãa }\end{array}$ \\
\hline Confiabilidade & 4,617 & 223 & 9 & 0,424 & $0,2<$ & Aceito $\mathrm{H}_{0}$ & $\begin{array}{l}\text { Os dados segu } \\
\text { distribuição }\end{array}$ \\
\hline esponsividade & 4,444 & 0,224 & 9 & 0,440 & $0,2 c$ & Aceito $\mathrm{H}_{0}$ & $\begin{array}{r}\text { Os dad } \\
\text { distril }\end{array}$ \\
\hline Garantia & 4,452 & 0,260 & 9 & 0,268 & 0,590 & Aceito $\mathrm{H}_{0}$ & $\begin{array}{l}\text { Os dac } \\
\text { distri }\end{array}$ \\
\hline Empat & 69 & 0,285 & 9 & 0,324 & 0,4 & Ac & $\begin{array}{l}\text { Os dados seguem uma } \\
\text { distribuição normal }\end{array}$ \\
\hline \multicolumn{8}{|c|}{ Valores observados (percepção) } \\
\hline Dimensão & Média $(\mu)$ & $\begin{array}{c}\text { Desvio } \\
\text { Padrão }(\sigma)\end{array}$ & $\mathbf{N}$ & Valor AD & Valor_P & Decisão & Conclusão \\
\hline Tangibilidade & 3,921 & 0,241 & 9 & 0,216 & 0,775 & Aceit & $\begin{array}{l}\text { Os dados } \\
\text { distribu }\end{array}$ \\
\hline Confiabilidade & 204 & 3 & 9 & 0 & 5 & A & $\begin{array}{l}\text { Os dados seguem uma } \\
\text { distribuição normal }\end{array}$ \\
\hline
\end{tabular}


$\underline{\text { Tabela } 7 \text {-Teste de aderência para as atividades relacionadas à Pesquisa }}$

(conclusão)

\begin{tabular}{|c|c|c|c|c|c|c|c|}
\hline \multicolumn{8}{|c|}{ Valores observados (percepção) } \\
\hline Dimensão & Média $(\mu)$ & $\begin{array}{c}\text { Desvio } \\
\text { Padrão }(\sigma)\end{array}$ & $\mathbf{N}$ & Valor AD & Valor_P & Decisão & Conclusão \\
\hline Responsividade & 3,242 & 0,355 & 9 & 0,319 & 0,461 & Aceito $\mathrm{H}_{0}$ & $\begin{array}{l}\text { Os dados seguem uma } \\
\text { distribuição normal }\end{array}$ \\
\hline Garantia & 3,255 & 0,484 & 9 & 0,157 & 0,926 & Aceito $\mathrm{H}_{0}$ & $\begin{array}{l}\text { Os dados seguem uma } \\
\text { distribuição normal }\end{array}$ \\
\hline Empatia & 2,942 & 0,298 & 9 & 0,412 & 0,264 & Aceito $\mathrm{H}_{0}$ & $\begin{array}{l}\text { Os dados seguem uma } \\
\text { distribuição normal }\end{array}$ \\
\hline
\end{tabular}

Tabela 8 - Teste de aderência para as atividades relacionadas ao Ensino

\begin{tabular}{|c|c|c|c|c|c|c|c|}
\hline \multicolumn{8}{|c|}{ Valores esperados (expectativa) } \\
\hline Dimensão & Média $(\mu)$ & $\begin{array}{l}\text { Desvio } \\
\text { Padrão } \\
(\sigma)\end{array}$ & $\mathbf{N}$ & Valor AD & Valor_P & Decisão & Conclusão \\
\hline Tangibilidade & 3,896 & 0,151 & 9 & 0,335 & 0,421 & Aceito $\mathrm{H}_{0}$ & $\begin{array}{c}\text { Os dados seguem } \\
\text { uma distribuição } \\
\text { normal }\end{array}$ \\
\hline Confiabilidade & 4,552 & 0,321 & 9 & 1,571 & $<0,005$ & Rejeito $\mathrm{H}_{0}$ & $\begin{array}{l}\text { Os dados não } \\
\text { seguem uma } \\
\text { distribuição normal }\end{array}$ \\
\hline Responsividade & 4,432 & 0,296 & 9 & 1,189 & $<0,005$ & Rejeito $\mathrm{H}_{0}$ & $\begin{array}{l}\text { Os dados não } \\
\text { seguem uma } \\
\text { distribuição normal } \\
\text { Os dados não }\end{array}$ \\
\hline Garantia & 4,415 & 0,269 & 9 & 0,970 & 0,008 & Rejeito $\mathrm{H}_{0}$ & $\begin{array}{c}\text { seguem uma } \\
\text { distribuição normal }\end{array}$ \\
\hline Empatia & 3,917 & 0,215 & 9 & 0,543 & 0,117 & Aceito $\mathrm{H}_{0}$ & $\begin{array}{c}\text { Os dados seguem } \\
\text { uma distribuição } \\
\text { normal }\end{array}$ \\
\hline \multicolumn{8}{|c|}{ Valores observados (percepção) } \\
\hline Dimensão & Média $(\mu)$ & $\begin{array}{l}\text { Desvio } \\
\text { Padrão } \\
(\sigma)\end{array}$ & $\mathbf{N}$ & Valor AD & Valor_P & Decisão & Conclusão \\
\hline Tangibilidade & 3,862 & 0,236 & 9 & 0,395 & 0,293 & Aceito $\mathrm{H}_{0}$ & $\begin{array}{c}\text { Os dados seguem } \\
\text { uma distribuição } \\
\text { normal }\end{array}$ \\
\hline Confiabilidade & 3,107 & 0,133 & 9 & 0,278 & 0,560 & Aceito $\mathrm{H}_{0}$ & $\begin{array}{c}\text { Os dados seguem } \\
\text { uma distribuição } \\
\text { normal }\end{array}$ \\
\hline Responsividade & 3,191 & 0,193 & 9 & 0,444 & 0,217 & Aceito $\mathrm{H}_{0}$ & $\begin{array}{c}\text { Os dados seguem } \\
\text { uma distribuição } \\
\text { normal }\end{array}$ \\
\hline Garantia & 3,144 & 0,307 & 9 & 0,556 & 0,108 & Aceito $\mathrm{H}_{0}$ & $\begin{array}{c}\text { Os dados seguem } \\
\text { uma distribuição } \\
\text { normal }\end{array}$ \\
\hline Empatia & 2,835 & 0,221 & 9 & 0,433 & 0,433 & Aceito $\mathrm{H}_{0}$ & $\begin{array}{c}\text { Os dados seguem } \\
\text { uma distribuição } \\
\text { normal }\end{array}$ \\
\hline
\end{tabular}


Tabela 9 - Teste de aderência para as atividades relacionadas à Extensão

\begin{tabular}{|c|c|c|c|c|c|c|c|}
\hline \multicolumn{8}{|c|}{ Valores esperados (expectativa) } \\
\hline Dimensão & Média $(\mu)$ & $\begin{array}{l}\text { Desvio } \\
\text { Padrão } \\
(\sigma)\end{array}$ & $\mathbf{N}$ & Valor AD & Valor_P & Decisão & Conclusão \\
\hline Tangibilidade & 3,886 & 0,287 & 8 & 0,441 & 0,211 & Aceito $\mathrm{H}_{0}$ & $\begin{array}{c}\text { Os dados seguem } \\
\text { uma distribuição } \\
\text { normal }\end{array}$ \\
\hline Confiabilidade & 4,597 & 0,227 & 8 & 0,227 & 0,724 & Aceito $\mathrm{H}_{0}$ & $\begin{array}{c}\text { Os dados seguem } \\
\text { uma distribuição } \\
\text { normal }\end{array}$ \\
\hline Responsividade & 4,529 & 0,385 & 8 & 0,835 & 0,017 & Rejeito $\mathrm{H}_{0}$ & $\begin{array}{c}\text { Os dados não } \\
\text { seguem uma } \\
\text { distribuição normal }\end{array}$ \\
\hline Garantia & 4,499 & 0,357 & 8 & 0,205 & 0,805 & Aceito $\mathrm{H}_{0}$ & $\begin{array}{c}\text { Os dados seguem } \\
\text { uma distribuição } \\
\text { normal }\end{array}$ \\
\hline Empatia & 4,070 & 0,431 & 8 & 0,218 & 0,757 & Aceito $\mathrm{H}_{0}$ & $\begin{array}{c}\text { Os dados seguem } \\
\text { uma distribuição } \\
\text { normal }\end{array}$ \\
\hline \multicolumn{8}{|c|}{ Valores observados (percepção) } \\
\hline Dimensão & Média $(\mu)$ & $\begin{array}{l}\text { Desvio } \\
\text { Padrão } \\
\text { ( } \sigma)\end{array}$ & $\mathbf{N}$ & Valor AD & Valor_P & Decisão & Conclusão \\
\hline Tangibilidade & 3,893 & 0,222 & 8 & 0,311 & 0,470 & Aceito $\mathrm{H}_{0}$ & $\begin{array}{c}\text { Os dados seguem } \\
\text { uma distribuição } \\
\text { normal }\end{array}$ \\
\hline Confiabilidade & 3,027 & 0,440 & 8 & 0,664 & 0,051 & Aceito $\mathrm{H}_{0}$ & $\begin{array}{c}\text { Os dados seguem } \\
\text { uma distribuição } \\
\text { normal }\end{array}$ \\
\hline Responsividade & 3,396 & 0,375 & 8 & 0,955 & 0,008 & Rejeito $\mathrm{H}_{0}$ & $\begin{array}{c}\text { Os dados não } \\
\text { seguem uma } \\
\text { distribuição normal }\end{array}$ \\
\hline Garantia & 3,217 & 0,434 & 8 & 0,396 & 0,280 & Aceito $\mathrm{H}_{0}$ & $\begin{array}{c}\text { Os dados seguem } \\
\text { uma distribuição } \\
\text { normal }\end{array}$ \\
\hline Empatia & 2,926 & 0,334 & 8 & 0,276 & 0,551 & Aceito $\mathrm{H}_{0}$ & $\begin{array}{c}\text { Os dados seguem } \\
\text { uma distribuição } \\
\text { normal }\end{array}$ \\
\hline
\end{tabular}

Tabela 10 - Teste de aderência para as atividades relacionadas aos Serviços Administrativos Revista Produção Online. Florianópolis, SC, v. 19, n. 2, p. 722-758, 2019. 


\begin{tabular}{|c|c|c|c|c|c|c|c|}
\hline \multicolumn{8}{|c|}{ Valores esperados (expectativa) } \\
\hline Dimensão & Média $(\mu)$ & $\begin{array}{l}\text { Desvio } \\
\text { Padrão } \\
(\sigma)\end{array}$ & $\mathbf{N}$ & Valor AD & Valor_P & Decisão & Conclusão \\
\hline Tangibilidade & 3,940 & 0,194 & 8 & 0,498 & 0,146 & Aceito $\mathrm{H}_{0}$ & $\begin{array}{c}\text { Os dados seguem } \\
\text { uma distribuição } \\
\text { normal }\end{array}$ \\
\hline Confiabilidade & 4,759 & 0,114 & 8 & 0,799 & 0,022 & Rejeito $\mathrm{H}_{0}$ & $\begin{array}{l}\text { Os dados não } \\
\text { seguem uma } \\
\text { distribuição normal }\end{array}$ \\
\hline Responsividade & 4,655 & 0,103 & 8 & 0,305 & 0,486 & Aceito $\mathrm{H}_{0}$ & $\begin{array}{c}\text { Os dados seguem } \\
\text { uma distribuição } \\
\text { normal }\end{array}$ \\
\hline Garantia & 4,655 & 0,128 & 8 & 0,310 & 0,472 & Aceito $\mathrm{H}_{0}$ & $\begin{array}{c}\text { Os dados seguem } \\
\text { uma distribuição } \\
\text { normal }\end{array}$ \\
\hline Empatia & 4,138 & 0,293 & 8 & 0,268 & 0,574 & Aceito $\mathrm{H}_{0}$ & $\begin{array}{c}\text { Os dados seguem } \\
\text { uma distribuição } \\
\text { normal }\end{array}$ \\
\hline \multicolumn{8}{|c|}{ Valores observados (percepção) } \\
\hline Dimensão & Média $(\mu)$ & $\begin{array}{l}\text { Desvio } \\
\text { Padrão } \\
\quad(\sigma)\end{array}$ & $\mathbf{N}$ & Valor AD & Valor_P & Decisão & Conclusão \\
\hline Tangibilidade & 4,184 & 0,307 & 8 & 0,194 & 0,837 & Aceito $\mathrm{H}_{0}$ & $\begin{array}{c}\text { Os dados seguem } \\
\text { uma distribuição } \\
\text { normal }\end{array}$ \\
\hline Confiabilidade & 3,025 & 0,246 & 8 & 0,296 & 0,508 & Aceito $\mathrm{H}_{0}$ & $\begin{array}{c}\text { Os dados seguem } \\
\text { uma distribuiçãa } \\
\text { normal }\end{array}$ \\
\hline Responsividade & 3,142 & 0,282 & 8 & 0,163 & 0,910 & Aceito $\mathrm{H}_{0}$ & $\begin{array}{l}\text { Os dados seguem } \\
\text { uma distribuição } \\
\text { normal }\end{array}$ \\
\hline Garantia & 2,941 & 0,199 & 8 & 0,698 & 0,041 & Rejeito $\mathrm{H}_{0}$ & $\begin{array}{l}\text { Os dados não } \\
\text { seguem uma } \\
\text { distribuição normal }\end{array}$ \\
\hline Empatia & 2,845 & 0,336 & 8 & 0,965 & 0,007 & Rejeito $\mathrm{H}_{0}$ & $\begin{array}{l}\text { Os dados não } \\
\text { seguem uma } \\
\text { distribuição normal }\end{array}$ \\
\hline
\end{tabular}

De acordo com a análise dos resultados, $80 \%$ dos dados seguem uma distribuição normal. Assumiu-se, assim, a normalidade dos dados para todas as dimensões avaliadas. Compreende-se que, dessa forma, pode-se utilizar estatísticas paramétricas para as análises (FIELD, 2009).

\subsection{Teste de hipóteses}

Os resultados obtidos por meio das análises preliminares demonstram um comportamento semelhante entre as cinco dimensões da escala ServQual referentes aos serviços relacionados ao Ensino, Pesquisa, Extensão e Serviços Administrativos. Assim, no intuito de verificar se esses resultados de fato retratam a realidade da 
amostra analisada, executou-se um teste de hipóteses. Segundo Montgomery e Runger (2014) esse teste corresponde ao procedimento de tomada de decisão sobre uma determinada hipótese. Essa ferramenta estatística, ainda segundo esses autores, é amplamente utilizada visto que, normalmente, muitos tipos de problemas de tomada de decisão, testes ou experimentos podem ser formulados seguindo o modelo de teste de hipóteses.

Dentre os testes de hipóteses existentes, optou-se pela análise de variância, ANOVA One Way. Esse teste, segundo Larson e Farber (2015), permite comparar a média de duas ou mais amostras a partir da análise da dispersão presente no conjunto de dados. Diante disso, a realização da análise de variância permitirá verificar se as cinco dimensões da ferramenta ServQual apresentam comportamentos semelhantes nos diferentes grupos estudados.

Para a realização da análise de variância, inicialmente faz-se necessário estabelecer as hipóteses que serão testadas, sendo elas:

$\mathbf{H}_{0}$ : Não existem diferenças significativas entre as médias dos Gaps das dimensões do ServQual entre os setores Ensino, Pesquisa, Extensão e Serviços Administrativos;

$\mathbf{H}_{1}$ : Pelo menos um dos quatro setores apresenta média diferenciada do Gap de uma das dimensões do ServQual.

O teste de hipóteses foi realizado no Software Minitab, em que os dados referentes a todos os 219 respondentes foram inseridos e distribuídos em grupos conforme os setores avaliados (Tabela 11).

Tabela 11 - ANOVA One-Way para as dimensões ServQual

\begin{tabular}{ccccccc}
\hline Dimensão & $\begin{array}{c}\text { Fonte de } \\
\text { variação }\end{array}$ & GL & SQ & MQ & F & Valor-P \\
\hline Tangibilidade & Setor & 3 & 2,895 & 0,964936 & 1,50 & 0,2149 \\
Confiabilidade & Setor & 3 & 2,618 & 0,872690 & 1,19 & 0,3160 \\
Responsividade & Setor & 3 & 2,667 & 0,888838 & 0,93 & 0,4259 \\
Garantia & Setor & 3 & 4,840 & 1,61344 & 1,87 & 0,1355 \\
Empatia & Setor & 3 & 6,828 & 2,27592 & 2,23 & 0,0856 \\
\hline
\end{tabular}

Montgomery e Ranger (2014) apresentam como uma alternativa para reportar os resultados de um teste de hipóteses a delimitação de um nível de significância $(\alpha)$. Ainda sob a ótica desses autores, para aceitar ou rejeitar a hipótese nula, deve-se 
avaliar o valor-P, que é calculado a partir dos dados fornecidos e corresponde ao menor nível de significância que permite a rejeição da hipótese nula $\left(\mathrm{H}_{0}\right)$. Assim, assumindo um $\alpha=0,05$, a hipótese nula será rejeitada se o valor-P calculado for inferior ao nível de significância estabelecido e, caso assuma um valor superior ao $\alpha$, a hipótese nula deverá ser aceita.

Como podem ser observados na Tabela 11, todos os valores-P obtidos a partir do teste de hipóteses são superiores ao nível de significância definido $(\alpha=0,05)$ e, dessa forma, deve-se aceitar a hipótese nula $\left(\mathrm{H}_{0}\right)$, que afirma que não existem diferenças significativas entre as médias dos Gaps correspondentes às dimensões do ServQual entre os setores avaliados.

Ao realizar a comparação entre diferentes grupos é importante salientar que a diferença significativa não ocorre quando as médias dos processos avaliados se sobrepõem com os intervalos de confiança dos mesmos.

A Figura 2 apresenta os intervalos dos Gaps das cinco dimensões do ServQual para os setores Ensino, Pesquisa, Extensão e Serviços Administrativos, considerando um intervalo de confiança de $95 \%$ para a média.

Assim, percebe-se que há similaridade estatística entre os serviços relacionados ao Ensino, a Pesquisa, a Extensão e Administrativos em todas as dimensões do ServQual, uma vez que as médias dos setores se sobrepõem nos intervalos de confiança. Esse resultado é reforçado pelo valor-P encontrado para cada uma das dimensões avaliadas.

Diante desses resultados, conclui-se que os diferentes grupos de discentes que participaram do presente estudo possuem percepções semelhantes com relação às dimensões tangibilidade, confiabilidade, responsividade, garantia e empatia.

As análises preliminares e o teste de hipóteses permitiram que as hipóteses estabelecidas para esta pesquisa fossem devidamente avaliadas. A hipótese 1, que considerava que a dimensão Responsividade apresentaria o maior Gap entre a qualidade percebida e a expectativa dos discentes, foi refutada, uma vez que a dimensão Confiabilidade apresentou o maior Gap negativo e a dimensão Tangibilidade apresentou o maior Gap positivo em todos os grupos avaliados. De acordo com as observações feitas pelos discentes, pode-se inferir que a Tangibilidade apresenta uma melhor avaliação devido à infraestrutura dos laboratórios da instituição. Por sua vez, as propostas de melhoria relacionadas à Confiabilidade dos 
serviços, concentram-se na definição de prazos e padronização dos serviços, além de melhorias nas relações que envolvem técnicos, discentes e docentes dos diferentes setores da instituição.

Figura 2 - Intervalos das dimensões do ServQual versus Setor

\begin{tabular}{|c|c|}
\hline 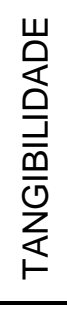 & 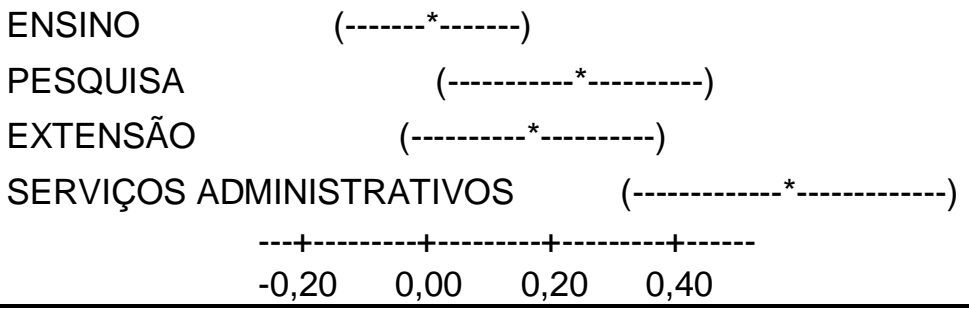 \\
\hline 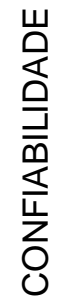 & 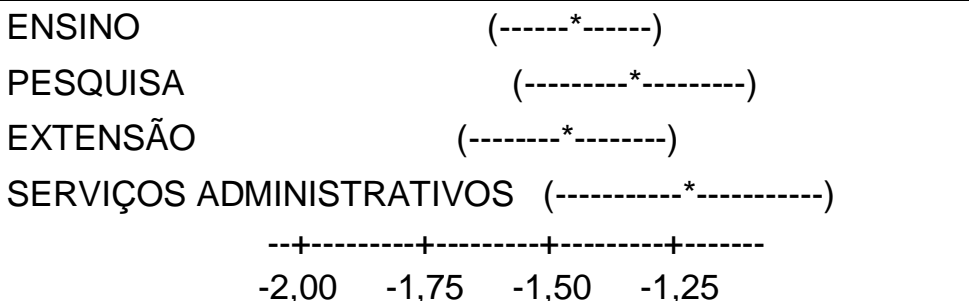 \\
\hline 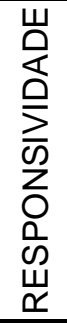 & 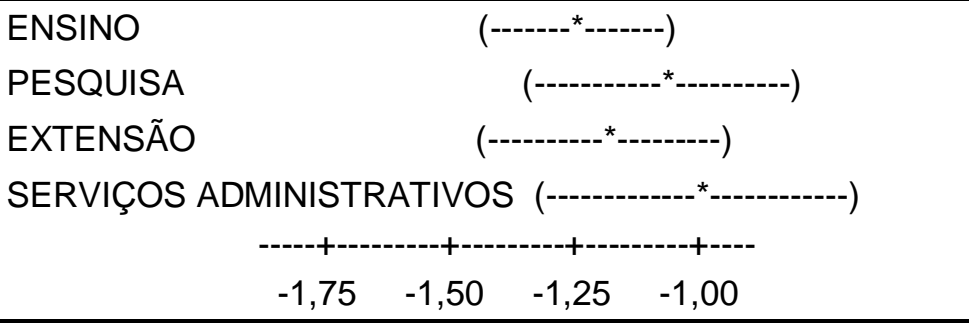 \\
\hline 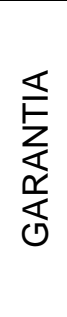 & 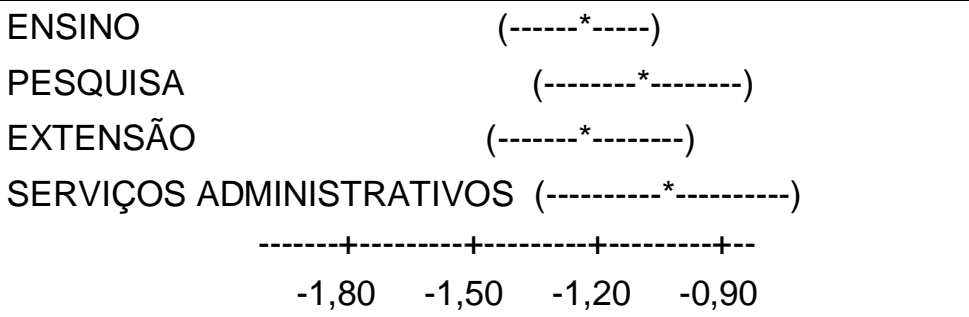 \\
\hline 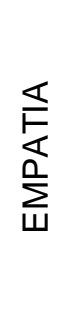 & 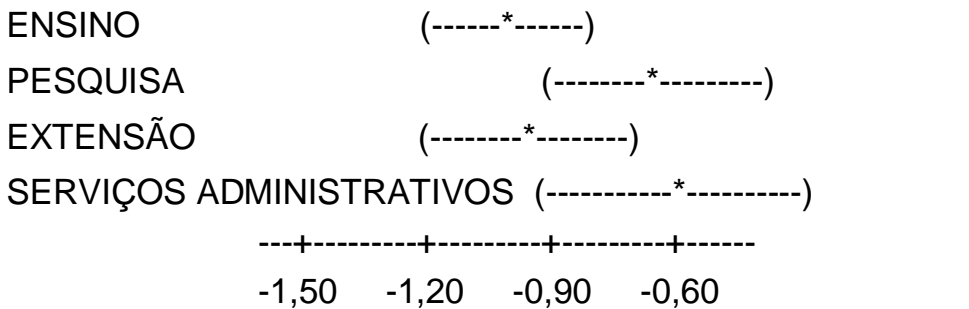 \\
\hline
\end{tabular}

A hipótese 2, que considera que a avaliação feita por discentes que participam de alguma entidade estudantil seria diferente daquela realizada pelos demais alunos, também foi refutada. O teste de hipóteses demonstrou que as cinco dimensões da ferramenta ServQual avaliadas comportam-se de maneira semelhante nos diferentes grupos analisados. Esse comportamento pode ser justificado pela ferramenta utilizada para essa análise, uma vez que o questionário ServQual é capaz de convergir e 
relacionar diferentes perguntas para a avaliação de uma mesma dimensão do serviço, contribuindo, dessa forma, para que a análise seja mais coerente.

\subsection{Análise de variância}

Para avaliar a coerência entre os respondentes foi utilizado o teste t para 2 amostras. As hipóteses estabelecidas foram:

$\mathrm{H}_{0}$ : Não há diferença estatística entre as notas atribuídas pelos respondentes.

$\mathrm{H}_{1}$ : Há diferença estatística entre as notas atribuídas pelos respondentes.

As Tabelas 12 a 15 apresentam os resultados obtidos.

Tabela 12 - Análise de variância para as atividades relacionadas à Pesquisa

\begin{tabular}{cccccc}
\hline & N & Média & $\begin{array}{c}\text { Desvio } \\
\text { Padrão }\end{array}$ & $\begin{array}{c}\text { Erro da } \\
\text { média }\end{array}$ & Valor_P \\
\hline Tangibilidade_Percepção & 9 & 3,921 & 0,241 & 0,080 & 0,254 \\
Tangibilidade_Expectativa & 9 & 3,847 & 0,221 & 0,074 & \\
& & & & & \\
Confiabilidade_Percepção & 9 & 3,204 & 0,323 & 0,110 & 1 \\
Confiabilidade_Expectativa & 9 & 4,617 & 4,617 & 0,074 & \\
& & & & & \\
Responsividade_Percepção & 9 & 3,242 & 0,355 & 0,120 & 1 \\
Responsividade_Expectativa & 9 & 4,444 & 0,224 & 0,075 & \\
Garantia_Percepção & 9 & 3,255 & 0,484 & 0,484 & 1 \\
Garantia_Expectativa & 9 & 4,452 & 0,260 & 0,087 & \\
Empatia_Percepção & 9 & 2,942 & 0,298 & 0,099 & 1 \\
Empatia_Expectativa & 9 & 3,692 & 0,285 & 0,095 &
\end{tabular}

Tabela 13 - Análise de variância para as atividades relacionadas ao Ensino

\begin{tabular}{cccccc} 
Tangibilidade_Percepção & 9 & 3,862 & $\begin{array}{c}\text { Média } \\
\text { Padrão }\end{array}$ & $\begin{array}{c}\text { Erro da } \\
\text { média } \\
0,079\end{array}$ & $\begin{array}{c}\text { Valor_P } \\
\text { Tangibilidade_Expectativa }\end{array}$ \\
& 9 & 3,890 & 0,151 & 0,050 & \\
Confiabilidade_Percepção & 9 & 3,107 & 0,133 & 0,044 & 1 \\
Confiabilidade_Expectativa & 9 & 0,044 & 0,321 & 0,110 & \\
& & & & & \\
Responsividade_Percepção & 9 & 3,191 & 0,193 & 0,064 & \\
Responsividade_Expectativa & 9 & 4,432 & 0,296 & 0,099 & \\
Garantia_Percepção & 9 & 3,144 & 0,307 & 0,100 & 1 \\
Garantia_Expectativa & 9 & 4,415 & 0,269 & 0,269 & \\
Empatia_Percepção & 9 & 2,835 & 0,220 & 0,073 & 1 \\
Empatia_Expectativa & 9 & 3,917 & 0,215 & 0,072 & \\
\hline
\end{tabular}

Tabela 14 - Análise de variância para as atividades relacionadas à Extensão 


\begin{tabular}{cccccc} 
& N & Média & $\begin{array}{c}\text { Desvio } \\
\text { Padrão }\end{array}$ & $\begin{array}{c}\text { Erro da } \\
\text { média }\end{array}$ & Valor_P \\
\hline Tangibilidade_Percepção & 8 & 3,893 & 0,222 & 0,079 & 0,481 \\
Tangibilidade_Expectativa & 8 & 3,886 & 0,287 & 0,100 & \\
& & & & & \\
Confiabilidade_Percepção & 8 & 3,027 & 0,440 & 0,160 & 1 \\
Confiabilidade_Expectativa & 8 & 4,597 & 0,227 & 0,080 & \\
& & & & & \\
Responsividade_Percepção & 8 & 3,396 & 0,375 & 0,130 & 1 \\
Responsividade_Expectativa & 8 & 4,529 & 4,529 & 0,140 & \\
& & & & & \\
Garantia_Percepção & 8 & 3,217 & 0,434 & 0,150 & 1 \\
Garantia_Expectativa & 8 & 4,499 & 0,357 & 0,130 & \\
Empatia_Percepção & 8 & 2,926 & 0,334 & 0,120 & 1 \\
Empatia_Expectativa & 8 & 4,070 & 0,431 & 0,150 & \\
\hline
\end{tabular}

Tabela 15 - Análise de variância para as atividades relacionadas aos Serviços Administrativos

\begin{tabular}{cccccc} 
& N & Média & $\begin{array}{c}\text { Desvio } \\
\text { Padrão }\end{array}$ & $\begin{array}{c}\text { Erro da } \\
\text { média }\end{array}$ & Valor_P \\
\hline Tangibilidade_Percepção & 8 & 4,184 & 0,306 & 0,110 & 0,06 \\
Tangibilidade_Expectativa & 8 & 3,940 & 0,194 & 0,068 & \\
Confiabilidade_Percepção & 8 & 3,025 & 0,246 & 0,087 & 1 \\
Confiabilidade_Expectativa & 8 & 4,759 & 0,114 & 0,040 & \\
Responsividade_Percepção & 8 & 3,142 & 0,282 & 0,100 & 1 \\
Responsividade_Expectativa & 8 & 4,655 & 0,103 & 0,036 & \\
& & & & & \\
Garantia_Percepção & 8 & 2,941 & 0,199 & 0,070 & 1 \\
Garantia_Expectativa & 8 & 4,655 & 0,128 & 0,045 & \\
Empatia_Percepção & 8 & 2,845 & 0,336 & 0,120 & 1 \\
Empatia_Expectativa & 8 & 4,138 & 0,293 & 0,100 & \\
\hline
\end{tabular}

Como o valor de P é maior do que o nível de significância de $5 \%(\alpha=0,05)$ para todas as dimensões analisadas, aceita-se a hipótese nula $\left(\mathrm{H}_{0}\right)$. Portanto, pode-se concluir que não existem divergências entre as opiniões dos discentes que participaram da pesquisa, justificando os baixos valores dos desvios padrão obtidos e apresentados nas Tabelas 2 a 5.

\section{CONCLUSÃO}

O presente estudo teve como objetivo identificar as lacunas existentes entre as expectativas e percepções dos discentes de uma Instituição Pública de Ensino Superior com relação à qualidade dos serviços prestados. A partir da aplicação da 
ferramenta ServQual foi possível elaborar um diagnóstico para cada um dos principais serviços da instituição (o Ensino, a Pesquisa, a Extensão e os Serviços Administrativos). $\mathrm{O}$ fato dos discentes que responderam ao questionário terem sido aqueles que, comprovadamente, foram clientes dos serviços prestados pela instituição em cada um dos setores avaliados permitiu atingir o objetivo proposto.

Como resultados principais, observou-se que a dimensão Tangibilidade obteve a melhor avaliação em todos os setores e a dimensão Confiabilidade é aquela que apresenta o maior Gap negativo e, portanto, requer uma maior atenção por parte da instituição. É importante ressaltar que os Gaps das cinco dimensões seguem uma mesma tendência nos quatro setores avaliados, e, além disso, muitas das oportunidades de melhoria citadas se repetem entre os diferentes grupos de respondentes. Logo, percebe-se que grande parte dos problemas apontados podem ser mitigados com ações que serão efetivas caso sejam propostas, implementadas e acompanhadas em conjunto entre os diferentes setores analisados.

Apesar de existirem algumas limitações quanto ao uso do ServQual, principalmente com relação à restrição na avaliação de apenas cinco dimensões de um serviço, foram tomadas algumas precauções com relação à validação do questionário aplicado: (a) Algumas adaptações foram realizadas na ferramenta ServQual, atendendo à solicitação dos alunos, como a inserção de alguns exemplos para melhor entendimento das afirmações. Essas adaptações permitiram relacionar as dimensões da qualidade avaliadas à realidade observada em uma instituição de ensino, assegurando o bom entendimento do questionário pelos discentes. (b) 0 questionário final foi submetido a um Comitê de Ética em Pesquisa (CEP). Todas as solicitações de alteração do comitê foram atendidas e o questionário foi aprovado. (c) O coeficiente Alfa de Cronbach foi calculado a partir das respostas obtidas. Todos os índices apresentaram-se como satisfatórios (acima de 0,8) reforçando a confiabilidade do questionário. Os testes estatísticos realizados mostraram coerência nas respostas dos discentes que participaram da pesquisa. Esses resultados reforçam a convergência das percepções com relação aos serviços prestados pela instituição de ensino, independentemente do curso ao qual o aluno está vinculado.

Um ponto que merece ser ressaltado é que a ferramenta não foi utilizada para avaliar aspectos intrínsecos do ensino e da pesquisa, por exemplo, e sim a prestação do serviço relacionado a essas atividades, como o lançamento de notas no tempo 
certo, a matrícula em disciplinas e o acesso aos laboratórios. Dessa forma, os resultados obtidos traduzem de fato a percepção de um dos principais grupos de clientes da instituição avaliada, os discentes.

Os discentes que participaram do presente estudo ainda demonstraram interesse genuíno em identificar os principais problemas e oportunidades de melhoria. A participação discente no processo de melhoria das instituições de ensino superior é uma grande oportunidade de desenvolvimento para todas as partes envolvidas, e deve ser levada em consideração.

Algumas limitações ao desenvolvimento desta pesquisa são apresentadas: (a) O objetivo do trabalho não foi avaliar a qualidade da instituição de ensino como um todo, e sim avaliar a qualidade dos serviços prestados por alguns órgãos dentro da instituição de ensino, propondo melhorias pontuais. (b) A dificuldade em se obter a relação de discentes que participam de grupos de representação estudantil, uma vez que esses grupos não são registrados na instituição e a rotatividade entre seus membros é alta, dificultando o contato com os mesmos. (c) Todos os clientes de uma instituição são importantes e devem ser considerados na determinação de processos de melhoria. Esta pesquisa concentrou-se apenas na visão dos discentes. Entretanto, deve-se ressaltar que, apesar das limitações, os objetivos propostos foram alcançados.

Mesmo considerando que os dados obtidos não possam ser generalizados, este diagnóstico poderá guiar algumas das ações dos gestores, ou servir como uma importante fonte para auxiliar na tomada de decisões. Os gestores da Instituição podem atuar diretamente nos serviços avaliados (Ensino, Pesquisa, Extensão e Serviços Administrativos), analisar as principais oportunidades de melhoria apontadas pelos discentes e utilizar as sugestões para transformar o cenário identificado. Assim, os resultados obtidos permitem à instituição uma base para aprimorar as suas práticas de maneira contínua e sistemática, aumentar o nível de satisfação dos discentes com relação aos serviços avaliados, além de estabelecer indicadores para acompanhar esses índices. Ou seja, é possível desenvolver projetos de melhoria contínua considerando como ponto de partida as sugestões de melhoria propostas, sendo uma importante contribuição da pesquisa realizada.

Sugere-se para pesquisas futuras a aplicação da ferramenta ServQual entre os gestores e docentes da instituição, com o intuito de comparar e identificar as 
diferenças existentes entre as percepções desses grupos com relação aos discentes. Propõe-se, ainda, que em aplicações futuras o questionário seja ainda mais adaptado caso se pretenda um maior detalhamento da percepção dos discentes/docentes, como avaliar serviços específicos dentro de um setor. Além disso, pode-se sugerir que a ferramenta seja adaptada e aplicada para avaliar cada um dos cursos da instituição e, dessa forma, identificar pontos fortes, pontos fracos e oportunidades de melhoria específicos a cada realidade.

\section{REFERÊNCIAS}

ALIDOUSTI, Sirous; ASADI, Asghar; KHOSROWJERDI, Mahmood. Libraries' Nationwide Membership (Ghadir) Quality Assessment Using SERVQUAL: Co-Libraries' Perspective. Iranian journal of Information Processing \& Management. Irã, v. 27, n. 1, p. 438-500, 2012.

BAHADORI, Mohammadkarim; SADEGHIFAR, Jamil; NEJATI, Mostafa; HAMOUZADEH, Pejman; HAKIMZADEH, Mostafa. Assessing quality of educational service by the SERVQUAL model: Viewpoints of paramedical students at Tehran university of medical science. Technics Technologies Education Management. Bósnia e Herzegovina, v. 6, n. 4, p. 1058-1065, 2011.

BRASIL. Constituição da república federativa do Brasil de 1988. Promulgada em 5 de outubro de 1988. Brasília, DF: Senado Federal. Disponível em http://www.planalto.gov.br/ccivil 03/constituicao/constituicaocompilado.htm. Acesso em: 30 outubro 2016.

BRASIL. Decreto $\mathrm{n}^{\circ}$ 6.096, de 24 de abril de 2007. Institui o Programa de Apoio a Planos de Reestruturação e Expansão das Universidades Federais - REUNI. Brasília, DF, 25 abr. 2007. Disponível em: http://www.planalto.gov.br/ccivil 03/ ato20072010/2007/decreto/d6096.htm. Acesso em: 16 maio 2016.

BRASIL. Decreto no 8.700, de 30 de março de 2016. Altera o Decreto no 8.670, de 12 de fevereiro de 2016, que dispõe sobre a programação orçamentária e financeira e estabelece o cronograma mensal de desembolso do Poder Executivo para o exercício de 2016. Diário Oficial da União, Brasília, DF, 30 mar. 2016. Disponível em: http://www.planalto.gov.br/ccivil 03/ ato2015-2018/2016/Decreto/D8700.htm. Acesso em: 16 maio 2016.

BRASIL. Lei n. 11.096, de 13 de janeiro de 2005. Institui o Programa Universidade para Todos ProUni, regula a doação de entidades beneficentes de assistência social no Ensino Superior; altera a Lei n. 10.891, de 9 de julho de 2004, e dá outras providências. Diário Oficial da União, Brasília, DF, 13 jan. 2005. Disponível em: http://prouniinscricao.mec.gov.br/prouni/legislacao.shtm. Acesso em: 16 maio 2016.

BRASIL. MINISTÉRIO DA EDUCAÇÃO, Instituto Nacional de Estudos e Pesquisas Educacionais Anísio Teixeira. Censo da Educação Superior 1997-2014. Disponível em: http://portal.inep.gov.br/web/censo-da-educacao-superior/evolucao-1980-a-2007. Acesso em: 16 maio 2016. 
BRYMAN, Alan; BELL, Emma. Business research methods. Oxford University Press, USA, 2011.

CID, Marília; SARAIVA, Margarida; PEREIRA, Dulce; SAMPAIO, Ana; BONITO, Jorge. Percepção estudantil da qualidade do ensino superior público no Alentejo (Portugal). Millenium, v. 39, p. 19-53, 2010.

DA SILVA LOURENÇO, Cléria Donizete; KNOP, Marcelo Ferreira Trezza. Ensino Superior em Administração e Percepção da Qualidade de Serviços: Uma aplicação da Escala ServQual. Revista Brasileira de Gestão de Negócios. Brasil, v. 13, n. 39, p. 219-233, 2011.

DE CARVALHO, Cristina Helena Almeida. Política para a educação superior no governo Lula expansão e financiamento. Revista do Instituto de Estudos Brasileiros, n. 58, p. 209-244, 2014. https://doi.org/10.11606/issn.2316-901X.v0i58p209-244

DEGTJARJOVA, Irina; LAPINA, Inga; Freidenfelds, Davis. Student as stakeholder: "voice of customer" in higher education quality development. Marketing and Management of Innovations, n. 2, p. 388-398, 2018. https://doi.org/10.21272/mmi.2018.2-30

FIELD, ANDY. Descobrindo a estatística usando o SPSS. 2.ed. São Paulo: Artmed, 2009.

FOWLER JUNIOR, F. J. Pesquisa de levantamento. 4. ed. Porto Alegre: Penso, 2011.

FREITAS, André Luís Policani; RODRIGUES, Sidilene Gonçalves. A avaliação da confiabilidade de questionários: uma análise utilizando o coeficiente de alfa de Cronbach. [online]. Bauru: nov. 2016. In: SIMPÓSIO DE ENGENHARIA DE PRODUÇÃO, 23., 2016. Anais... Disponível em: http://www.simpep.feb.unesp.br/anais simpep aux.php?e=12. Acesso em: 20 ago. 2016.

GALEEVA, Railya B. SERVQUAL application and adaptation for educational service quality assessments in Russian higher education. Quality Assurance in Education, v. 24, n. 3, p. 329 - 348, 2016. https://doi.org/10.1108/QAE-06-2015-0024

GANGA, Gillberto Miller Devós. Trabalho de Conclusão de Curso (TCC) na engenharia de produção: um guia prático de conteúdo e forma. São Paulo: Atlas, v. 361, 2012.

HORA, Henrique Rego Monteiro; MONTEIRO, Gina Torres Rego; ARICA, José. Confiabilidade em questionários para qualidade: um estudo de caso com o coeficiente Alfa de Cronbach. Produto \& Produção, v. 11, n. 2, p. 85-103, 2010.

https://doi.org/10.22456/1983-8026.9321

LARSON, Ron; FARBER, Betsy. Estatística aplicada. Tradução José Fernando Pereira Gonçalves; Revisão técnica Manoel Henrique Salgado. São Paulo: Pearson Education do Brasil, 2015.

LI, Qu; YING, Meng; WEI, Zhang. The improvement of higher education service quality based on SERVQUAL model. E -Business and E -Government (ICEE), 2011 International Conference on. China, p.1-3, 2011. https://doi.org/10.1109/ICEBEG.2011.5881646

LIKERT, Rensis. A technique for the measurement of attitudes. Archives of Psychology, V.22, n. 140, p. 44-53, 1932.

LUPO, Toni. A fuzzy ServQual based method for reliable measurements of education quality 
in Italian higher education area. Expert Systems with Applications, v. 40, n. 17, p. 7096 7110, 2013. https://doi.org/10.1016/i.eswa.2013.06.045

MALHOTRA, Naresh K. Pesquisa de marketing: uma orientação aplicada. Bookman Editora, 2012.

MONTGOMERRY, Douglas C; RUNGER; George, C. Applied Statistics and probability for Engineers. 6. ed. Arizona: John Wiley \& Sons, Inc., 2014. 836 p.

PIZZIO, Alex. Políticas de expansão do ensino superior no Brasil: a inclusão cidadã e os obstáculos ao estabelecimento da igualdade de oportunidades. Universidades, v. 66, n. 64, p. 75-87, 2015.

RODRIGUES, Iveti Magalia Caetano; DE LOURDES MACHADO, Maria; DE ARAÚJO, Joaquim Filipe Ferraz Esteves. Expansão do Ensino Superior no Brasil: avaliação como mecanismo para a garantia da qualidade. Comunicação apresentada para o 10 Fórum do Ensino Superior nos Países e Regiões de Língua Portuguesa, Universidade de Lisboa e Universidade de Coimbra, v. 14, 2011.

SAMPIERI, Roberto Fernández; COLLADO, Carlos Fernández; LUCIO, Pilar Baptista. Metodologia de pesquisa. 4. ed. São Paulo: McGraw-Hill, 2012.

SILVA, Sthéfany Marilac; NEVES, Sandra Miranda; CARVALHO, Henrique Duarte ; DE PAIVA, Emerson José. Análise bibliométrica sobre a avaliação da qualidade em instituições de ensino superior. [online]. Bauru: nov. 2016. In: SIMPÓSIO DE ENGENHARIA DE PRODUÇÃO, 23., 2016. Anais.... Disponível em <http://www.simpep.feb.unesp.br>. Acesso em: 20 ago. 2016.

SOBRINHO, José Dias. Avaliação e transformações da educação superior brasileira (19952009): do provão ao SINAES. Avaliação: Revista da Avaliação da Educação Superior, v. 15, n. 1, p.195-224, 2010. https://doi.org/10.1590/S1414-40772010000100011

STABBACK, Philip. Qu'est-ce qui fait un curriculum de qualité? UNESCO, International Bureau of Education, 2016. Disponível em:

http://unesdoc.unesco.org/images/0024/002439/243975f.pdf. Acesso em: 15 abril 2016.

WANG, Ruobin; YAN, Zhijun; LIU, Kecheng. An Empirical Study: Measuring the Service Quality of an e-Learning System with the Model of ZOT SERVQUAL. E-Business and EGovernment (ICEE), 2010 International Conference on. China, p. 5379-5382, 2010. https://doi.org/10.1109/ICEE.2010.1345

YOUSAPRONPAIBOON, Khanchitpol. SERVQUAL: Measuring Higher Education Service Quality in Thailand. Procedia - Social and Behavioral Sciences, v. 116, 5th World Conference on Educational Sciences, p. 1088-1095, 2014.

https://doi.org/10.1016/j.sbspro.2014.01.350

ZEITHAML, Valarie A.; PARASURAMAN, Ananthanarayanan; BERRY, Leonard L.

Delivering quality service: Balancing customer perceptions and expectations. New York: The Free Press, 1990.

ZEITHAML, Valarie A; PARASURAMAN, Ananthanarayanan; BERRY, Leonard L. SERVQUAL: A multiple-item scale for measuring consumer perceptions of service quality. Journal of retailing, v. 64 , n. 1, p. 12-40, 1988. 


\section{(2) (1)}

Artigo recebido em: 29/05/2018 e aceito para publicação em: 06/06/2019

DOI: http://dx.doi.org/10.14488/1676-1901.v19i2.3264 